\title{
Competition among coalitions in a cournot industry: a validation of the porter hypothesis
}

\section{Luca Lambertini $^{1}$ (D) $\cdot$ Giuseppe Pignataro $^{2} \cdot$ Alessandro Tampieri $^{3}$}

Received: 30 November 2018 / Revised: 26 August 2020 / Accepted: 9 October 2020 /

Published online: 31 December 2020

(c) The Author(s) 2020

\begin{abstract}
We determine the emergence of the Porter hypothesis in a large oligopoly setting where the industry-wide adoption of green technologies is endogenously determined as a result of competition among coalitions. We examine a framework where firms decide whether to be "brown" or "green" and compete in quantities. We find that the Porter hypothesis may emerge as a market configuration with all green firms spurred by environmental regulation, even if consumers are not environmentally concerned. We also single out the necessary and sufficient conditions under which the green grand coalition is socially optimal and therefore yields a win-win outcome. Then, we show that, if the environmental externality is steep enough, the tax rate maximising welfare in the initial industry configuration is a driver of the win-win solution. Finally, the analysis is extended in several directions.
\end{abstract}

Keywords Emission taxation · Pollution · Coalition stability · Green technology

JEL Classification $\mathrm{L} 13 \cdot \mathrm{L} 51 \cdot \mathrm{Q} 50$

We would like to thank the Editor Takashi Ui, two anonymous referees, Herbert Dawid, Michael Kopel, Joanna Poyago-Theotoky, and the audience at EARIE 2015 (Munich) for helpful comments and discussion. The usual disclaimer applies.

Luca Lambertini

luca.lambertini@unibo.it

Giuseppe Pignataro

giuseppe.pignataro@unibo.it

Alessandro Tampieri

alessandro.tampieri@unifi.it

1 Department of Economics, University of Bologna, Via San Giacomo 1, 40126 Bologna, Italy

2 Department of Economics, University of Bologna, Piazza Scaravilli 2, 40126 Bologna, Italy

3 Department of Economics, University of Florence, Via delle Pandette 9, 50127 Florence, Italy 


\section{Introduction}

Over the last two and a half centuries, since the very beginning of the industrial revolution, the bulk of industrial activities and the associated growth of the world economy have relied on brown energy delivered by the intensive exploitation of nonrenewable fossil fuels. It is now widely recognised that, should the economic system continue to go the brown way, the planet would run out of nonrenewable polluting resources in a matter of generations; exactly how many is a matter of opinions and estimates, but compared to the farthest future, it is certainly too small a number. For instance, Meadows et al. (1972) posited the existence of biophysical limits to growth, by predicting, with no changes to historical growth trends at that time, a "sudden and uncontrollable decline in both population and industrial capacity" by 2072. ${ }^{1}$ Additionally, future generations would inherit a planet which would be not only depleted of its pristine stock of resource, but heavily and perhaps even irreparably transfigured for the worse by climate change. Therefore, the question is whether a mix of private incentives and public policies may avoid the realization of this scenario. In this paper, we model this interplay to show that there may exist a way of combining profit incentives and policy tools to open up a green production path.

The key question is: will a number of energy-intensive industries, or even the whole world economy put itself on a sustainable growth path? ${ }^{2}$ Is there any hope that large populations of profit-seeking corporations will indeed turn themselves "green" as a reaction to a changing landscape, by positively responding to the introduction of new regulatory instruments building up binding limits to the environmental impact of firms' activities? According to the Porter hypothesis (Porter 1991), we may expect profit-seeking firms to behave like that, expecting to be better off if they do so, under appropriate policy stimuli.

Over more than 2 decades, the Porter hypothesis $(\mathrm{PH}, \text { hereafter })^{3}$ has generated a lively trend of thought about the existence of promising links between public environmental concern and firms' green strategies (or the lack thereof). The foundation of this debate asserts the possible existence of positive private returns to pollution control investment, possibly large enough to more than offset the cost of compliance. If this is true, then a win-win solution triggered by environmental regulation and driven by firms' reaction to it is in fact within reach. The essence of the PH boils down to the idea that strict but flexible environmental regulation encourages innovations enhancing competitiveness and contributing to make firms more profitable, and therefore happy to deliver a socially efficient outcome such as a clean (or at least cleaner) environment, as a by-product of their own private incentives. Porter and van der Linde (1995a, b), in particular, claim that pollution is often a waste of resources.

\footnotetext{
${ }^{1}$ Braat and Van Lierop (1987) summarises and surveys part of this literature.

${ }^{2}$ Here, 'sustainable' means not necessarily altogether green but simply 'low carbon', as the basic requirement boils down to reducing the emission rate of production and consumption activities to a level compatible with the environment's capability of absorbing and recycling $\mathrm{CO}_{2}$ and other greenhouse gases, as it did for ages before the beginning of the industrial revolution.

${ }^{3}$ See Wagner (2003), Ambec et al. (2013) and Lambertini $(2013,2017)$ for exhaustive surveys of the debate on the $\mathrm{PH}$.
} 
Under certain conditions, reducing the latter may drive an increase in firms' productivity and profits. Regulations therefore may ultimately help firms by unlocking unexpected profit opportunities. ${ }^{4}$ With this in mind, Porter and van der Linde's (1995a, b) view privileges market-based instruments (like emission taxes and the costly allocation of pollution rights) rather than command-and-control instruments (like environmental standards).

The stream of research generated by Porter and van der Linde (1995a, b) has investigated two different versions of the PH. The weak one claims that firms do respond to environmental regulation by investing in $\mathrm{R} \& \mathrm{D}$ for green (either abatement or replacement) technologies, which in turn may not lead to higher profits. The strong version of the $\mathrm{PH}$ says instead that one of the consequences of environmental policy is indeed that of increasing firms' profit perspectives. ${ }^{5}$ Obviously, the strong version has generated a debate which would not have stemmed out of the weak alternative formulation, the reason being that conventional wisdom has it that, in general, limiting firms' freedom should ultimately compromise their performance (cf. Palmer et al. 1995). Hence, one could say that, in a way, the effective merit of Porter and van der Linde's (1995a, b) papers has been that of convincing businessmen (among whom the $\mathrm{PH}$ is receiving a growing amount of attention) as well as policy makers about the potentially proficuous nature of environmental regulation.

If put into being, the virtuous mechanism embodied in the strong version of the hypothesis would produce a win-win outcome in which both a cleaner environment and a higher financial performance would go hand in hand, as a result of the reciprocal alignment of private (profit) incentives and social (welfare) incentives.

A distinctive feature of the $\mathrm{PH}$ is that it does not necessarily require any consumers' environmental awareness, relying primarily on pure profit incentives towards green innovations to neutralise environmental regulation. ${ }^{6}$ The $\mathrm{PH}$ is seemingly easier to implement if green consumption is in place. This is crucial to justify the trade-off between costs and benefits rendering the policy acceptable. Interestingly, Constantatos and Herrmann (2011) for instance propose a duopoly model where consumers recognise the green quality of the products only with a time lag. Thus, if regulation does not impose a simultaneous adoption of the eco-friendly technology among companies, a firm unilaterally may lose profits due to higher costs (which represents a direct effect) and reduce market share due to higher product prices (which is a strategic effect).

\footnotetext{
4 Since Gore (1993), politicians have viewed the green economy as a chance for growth and competitiveness for the industry. See also Wagner (2003).

5 A third version of the $\mathrm{PH}$ is known as narrow, and claims that flexible policy instruments outperform command-and-control instruments as for the resulting innovative incentives perceived by firms. For more on different formulations of the PH, see Jaffe and Palmer (1997).

6 Several studies (indeed, too many to be exhaustively mentioned here) have shown that world-wide, consumers' appetite for green products has increased significantly in the past years (see Kim and Choi 2005; Chen 2008, inter alia). The rise of such consciousness has resulted in significant environmental improvement (Reitman 1992). More companies around the world have reacted by developing ecofriendly products and pollution control investments (Chang 2011). Higher costs required for the progressive eco-technology are sustainable due to larger demands of green consumers.
} 
Unlike much of the current literature on environmental issues, including the $\mathrm{PH}$, the present analysis sets aside the assumption of environmental awareness. Our intention is to emphasize the possibility to obtain beneficial impacts from regulation simply due to the spontaneous firms's reaction to an environmental policy, the latter being not amplified or accompanied by any environmental consciousness on the part of consumers. No variations in demands or information of green technology adoption are needed, and we will assume that the representative consumer is characterised by a concave utility function where there is no room for the environmental impact of either consumption or production. Our point simply rests on the streamlined background idea that competitive pressure intensified by regulation pushes innovation and the resulting mechanism yields a Pareto efficient outcome for firms and society alike. ${ }^{7}$

The extant debate on the PH mostly relies on duopoly models (Ambec and Barla 2006; André et al. 2009; Constantatos and Herrmann 2011; Lambertini and Tampieri 2012; inter alia). ${ }^{8}$ We instead model an oligopolistic Cournot sector in partial equilibrium, where firms individually decide whether to be brown or green and then compete in quantities. ${ }^{9}$ Brown firms are subject to a tax rate on polluting emissions. On the other hand, green firms do not bear any taxes, but incur both a cost of investment in clean technology and a higher marginal production cost. To characterise firms' choices concerning the nature of their production technology, we resort to a tool borrowed from coalition theory (cf. d'Aspremont et al. 1983; Donsimoni 1985; Donsimoni et al. 1986; Thoron 1998). Using the concepts of internal and external stability of a coalition and assessing the welfare properties of the oligopoly under consideration, we identify the conditions on the two key parameters of the model, the emission tax and the exogenous R\&D cost of obtaining the green technology, such that the grand green coalition (1) is stable and (2) generates a win-win solution, thereby yielding a theoretical vindication of the $\mathrm{PH}$ in its strong formulation. Additionally, and most importantly, we show that the ex ante socially efficient tax rate is an appropriate incentive for firms to produce the win-win solution when the externality is strong enough.

From an empirical perspective, the possibility of systematically testing the emergence of the $\mathrm{PH}$ may be limited by several problems affecting the nature of the data as well as their availability. Indeed, regulatory compliance expenditures do not provide a truly exogenous measure of regulatory burden, since the amount of these

\footnotetext{
7 Note that our approach has the aim to highlight the role of competition, but does not exclude-in principle - the presence of environmental awareness. Intuitively, green consumers taking into account the firms' environmental attitude in shaping their consumption decisions would generally prefer to buy from firms endowed with green technologies. This would be in line with the results supporting the Porter hypothesis, and would plausibly facilitate the attainment of a win-win solution.

${ }^{8}$ It is worth stressing that the results obtained in Lambertini and Tampieri (2012) include overcompliance, or, firms' willingness to go green without regulation. In this respect, recent evidence has confirmed this possibility (see Ford et al. 2014).

9 Earlier analyses of the environmental implications of oligopolistic Cournot competition are in Katsoulacos and Xepapadeas (1995) and Fujiwara (2009), inter alia, where, however, the PH is not accounted for. A view of the PH based on agency costs and the internal organization of the firm is in Ambec and Barla (2002).
} 
costs also depends on the adaptability to regulation of an industry. In light of this, Jaffe and Palmer (1997) show the existence of a positive link between R\&D expenditures and pollution-abatement costs, as a proxy for the stringency of environmental regulation. Popp (2005) examine the presence of the PH by calibrating a model of induced R\&D when the outcome of innovation is uncertain. The strong version of the PH is here supported in some cases. Lanoie et al. (2011) test the significance of the PH using data on environmental policy, research and development, environmental performance, and economic performance. They find strong support for the weak version but no support for the strong version. In a recent work, Rexhäuser and Rammer (2014) show that only innovation processes influencing the resource efficiency of firms have a positive net return. Hence, the $\mathrm{PH}$ in its strong version does not hold in general, its emergence depending on the type of environmental innovation applied. This caveat notwithstanding, empirical analysis, and case studies seem to confirm that accurate design of regulatory measures, possibly in a flexible form, may indeed be conducive to win-win solutions (see Majumdar and Marcus 2001; Partzsch 2009; Costa and Ferrao 2010; Costa et al. 2010).

The paper also relies on the literature that focusses on the incentives in investing in technological change of pollution abatement (Milliman and Prince 1989). ${ }^{10}$ In particular, Requate and Unold (2003) analyse different policy instruments (taxes, auctioned permits, grandfathering, and emission standards) determining whether one of them gives more incentives to firms to adopt a pollution-abatement technology. Like the present analysis, Requate and Unold (2003) evaluates the conditions under which all firms or no firms will adopt the new technology. The main difference with the present paper is the focus on a competitive market rather than an oligopoly. This allows to ignore market competition and the strategic effect of adopting an environmental friendly technology. In turn, the stability analysis is not necessary, and the proportion of green or brown firms is determined by a comparison of costs which, in case of emission permits, depends on the number of brown firms.

Finally, the paper is indirectly related to the debate on international environmental agreements (IEAs), and in particular on its formulation in terms of non-cooperative game-theoretical models. ${ }^{11}$ This literature analyses the stability conditions for countries to be part of the IEA. Even if the context is clearly different, the link is both on the similarity of the theoretical analysis and on the same purpose of finding the conditions for a sustainable economy.

The remainder of the paper is organised as follows. The outline of the setup is in Sect. 2. Section 3 contains the analysis of coalition stability. Section 4 illustrates the necessary and sufficient conditions for the strong formulation of the $\mathrm{PH}$ to emerge at equilibrium. Different extensions of the basic setting are proposed in Sect. 5. Concluding remarks follow in Sect. 6.

\footnotetext{
${ }^{10}$ See Jaffe et al. (2003), for a survey.

${ }^{11}$ Seminal contributions are, among others, Carraro and Siniscalco (1993) and Barrett (1994). See Finus (2008) for a survey.
} 


\section{The model}

Consider a static market with $n \geq 2$ firms competing à la Cournot-Nash. ${ }^{12}$ Firms supply a homogeneous good, whose demand function is $p=a-Q$, where $a$ is a positive constant parameter measuring the choke price and $Q=\sum_{i=1}^{n} q_{i}$ aggregates all firms' individual output levels $q_{i}$. Firms can be of two types, either brown or green. A brown firm uses a polluting production technology and bears an emission tax rate $t>0$ imposed on each unit of output. Conversely, the production of green firms does not affect the environment, so that no taxation is levied on them. However, green companies face an investment cost $k \geq 0$ to implement their green production technology, and their marginal cost is higher than the one of brown firms. Without loss of generality, we normalise marginal production cost of a brown firm to zero, whereas the marginal production costs of a green firm are $c \in(0, a)$. This assumption reflects the higher cost of environmentally friendly resources in the real world. Reports from many countries show that, for instance, the energy produced with on/offshore wind and photovoltaics/thermal solar is more costly than the energy obtained from coal or natural gas. ${ }^{13}$

Before market competition takes place, each firm decides whether to be brown or green. Suppose that the industry is populated by $1 \leq m \leq n$ green firms and $n-m$ brown firms. The demand function is thus $p=a-m q_{g}-(n-m) q_{b}$, where subscripts $b$ and $g$ mnemonic for brown and green, respectively. The profits of a green firm are defined as $\pi_{g}=(p-c) q_{g}-k$, while those of a brown firm are $\pi_{b}=(p-t) q_{b}$.

In the remainder, we shall assume $a>t>c$. This assumption ensures that (1) the choke price is large enough for both types of firm to be viable, and (2) it may be convenient for a firm to be green (otherwise, for any $t<c$, it would not be convenient to opt for the green technology). The diffusion of green innovation and the role of environmental policy and competition matters in several markets. Evidence of this relationship emerges, for instance, in the European manufacturing sector (Rubashkina et al. 2015) and in the German energy market (Horbach and Rammer 2018).

As it is usually assumed, the environmental damage $S$ is a quadratic function of the quantity produced by brown firms:

$$
S=\frac{v\left(\sum_{b=m+1}^{n} q_{b}\right)^{2}}{2},
$$

where $v$ is a positive parameter.

\footnotetext{
12 See André et al. (2009) and Lambertini and Tampieri (2012) for a model of vertical differentiation in a duopoly framework with price and quantity competition, respectively. They both find that a policy regulation, i.e., a tax on brown technology can be Pareto-improving for all firms. Mohr (2002) propose a similar framework looking at the impacts of the technological spillovers.

13 See the OpenEI database for United States (http://en.openei.org/apps/TCDB/transparent_cost_datab ase), the 2015 report by the Fraunhofer Institute on Germany (https://www.ise.fraunhofer.de), and the 2010 report by Pasons Binckernhoff on Great Britain (www.pbworld.com/pdfs/regional/uk_europe/pb_ ptn_update2010.pdf), inter alia.
} 
Total tax revenue is $T=t \sum_{b=m+1}^{n} q_{b}$, whereas consumer surplus is measured by $\mathrm{CS}=Q^{2} / 2$. Hence, social welfare is defined as the sum of industry profits, consumer surplus, and tax revenue, minus the environmental damage:

$$
\mathrm{SW}=\sum_{g=1}^{m} \pi_{g}+\sum_{b=m+1}^{n} \pi_{b}+\mathrm{CS}+T-S .
$$

\section{Stability analysis}

To begin with, it is worth noting that the Cournot-Nash equilibrium of this industry is equivalent to that emerging in a situation in which there are two sets of asymmetric firms endowed with different marginal production costs. Here, one is indeed a production cost, while the other is mimicked by the emission tax rate. The market equilibrium is thus identified by the following pair of output levels:

$$
q_{g}^{m}=\frac{a-c(n-m+1)+t(n-m)}{1+n} ; q_{b}^{n-m}=\frac{a+c m-t(m+1)}{1+n},
$$

for each of the $m$ green firms and $n-m$ brown ones. The resulting individual equilibrium profits are:

$$
\begin{gathered}
\pi_{g}^{m}=\frac{[a-c(n-m+1)+t(n-m)]^{2}}{(1+n)^{2}}-k, \\
\pi_{b}^{n-m}=\frac{[a+c m-t(1+m)]^{2}}{(1+n)^{2}},
\end{gathered}
$$

given two generic groups of size $m$ and $n-m$, respectively. Observing profits $\pi_{g}^{m}$, it is evident that if $m=n$, the condition for the grand green coalition to be viable is $k \in[0, \underline{k})$, with $\underline{k}=(a-c)^{2} /(n+1)^{2}$.

The next step, which drives us into the realm of coalition theory, consists in taking the fully brown industry where $m=0$ as a benchmark, to examine the stability of the grand coalition made up by $n$ brown firms, in view of the incentive for a firm to become a green singleton. Fixing, respectively, $m=1$ in (2) and $m=0$ in (3), we obtain the following profit expressions:

$$
\pi_{g}^{1}=\frac{[a-c n+t(n-1)]^{2}}{(1+n)^{2}}-k ; \pi_{b}^{n}=\frac{(a-t)^{2}}{(1+n)^{2}},
$$

which measure, respectively, (1) the performance of a single firm becoming unilaterally green, and (2) that of each firm in the grand brown coalition. There exists an incentive to abandon the grand brown coalition unilaterally if and only if the following expression is positive: 


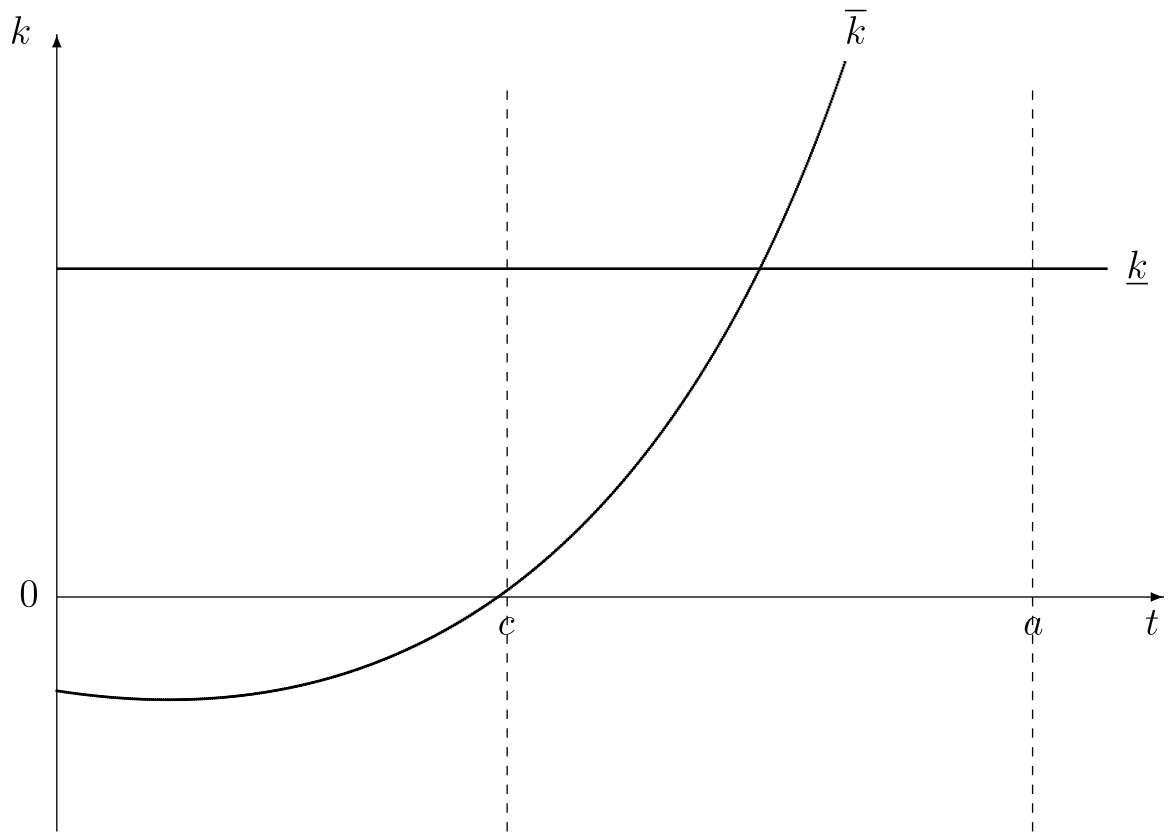

Fig. 1 The instability of the brown grand coalition

$$
\pi_{g}^{1}-\pi_{b}^{n}=\frac{n(t-c)[2(a-t)+n(t-c)]-(1+n)^{2} k}{(1+n)^{2}} .
$$

Observing (4), we may claim:

Lemma 1 The grand brown coalition is unstable for all $k \in(0, \bar{k})$, where:

$$
\bar{k} \equiv \frac{n(t-c)[2(a-t)+n(t-c)]}{(1+n)^{2}} .
$$

The critical values $\{\underline{k}, \bar{k}\}$ are drawn in Fig. 1 , in the space $(t, k)$. The vertical dashed lines at $t=c$ and $t=a$ delimit the admissible range. Since $\bar{k}$ becomes higher than $\underline{k}$ for admissible values of $t$ between $c$ and $a$, we have:

- for all $k \in[0, \min \{\underline{k}, \bar{k}\})$, the grand brown coalition is unstable and the grand green coalition is viable;

- as soon as $\bar{k}>\underline{k}$, for all $k \in(\underline{k}, \bar{k})$, the grand brown coalition is unstable, but the grand green coalition is not viable.

Lemma 1 implies that, if the R\&D cost of developing the green technology is sufficiently small, one has to expect unilateral deviations from the status quo ante in which all firms share the brown technology and bear the emission tax. This 
produces the additional question about how many firms will indeed choose to go green.

The intuition of the foregoing discussion can be found by observing Fig. 1. The possible market configurations depend on the combination between the technological features of the two firm types. When the fixed cost of the green technology $k$ is high and the tax is small, all firms choose to be brown. The opposite applies when $k$ is small and $t$ high. When both costs are high, there is not a clearcut advantage in choosing one technology or the other, and the equilibrium choice strategically depends on the competitors' choice: a mixed market configuration emerges. However, notice that $k \in(\underline{k}, \bar{k})$ does not ensure that the mixed market configuration is indeed stable. This point will be discussed in what follows.

To determine the equilibrium partition of the population of firms between the brown and green types, we resort to a stability condition borrowed from coalition theory and used in the literature discussing the optimal size of a cartel facing a competitive fringe, as in d'Aspremont et al. (1983), Donsimoni (1985), Donsimoni et al. (1986), and Thoron (1998).

We take as the object of our interest the stable green coalition of size $m \geq 1$. In the present model, a partition $\{m, n-m\}$ with $m$ green firms and $n-m$ brown ones is stable if no green firm desires to become brown (internal stability), and at the same time, no brown firm desires to shift to green (external stability).

Consider first the internal stability criterion. For the green coalition of size $m$ to be stable, there must exist no incentive for any of its member to deviate unilaterally and join the brown coalition. Let:

$$
\pi_{b}^{n-m+1}=\frac{[a+c(m-1)-t m]^{2}}{(1+n)^{2}},
$$

denote the profits of a brown firm, when a single green firm quits the $m$-sized green coalition to become brown, thereby increasing the numerosity of the brown coalition to $n-m+1$.

Likewise, one can easily compute the profits of a green firm when a brown firm changes its type becoming a green one, thereby increasing the size of the green coalition to $m+1$ :

$$
\pi_{g}^{m+1}=\frac{[a-t+(n-m)(t-c)]^{2}}{(1+n)^{2}}-k .
$$

Hence, the stability conditions for a market structure with $m$ green firms and $n-m$ brown firms are:

$$
\left\{\begin{array}{l}
\pi_{g}^{m} \geq \pi_{b}^{n-m+1}(\text { internal stability }) \\
\pi_{b}^{n-m} \geq \pi_{g}^{m+1}(\text { external stability })
\end{array}\right.
$$

A coalition is defined as internally stable if and only if, for $m \geq 1$, the profits of each single green firm associated with other $m-1$ green firms are higher than those the 
same firm would attain by moving from the green coalition towards the alternative brown coalition. Conversely, a coalition of $m$ green firms is defined as externally stable if and only if, for $m \leq n-1$, there is no incentive for a firm in isolation to move from the brown coalition towards the green one. We already know that a way of reading Lemma 1 is that the degenerate coalition consisting in the singleton $m=1$ is externally stable for all $k \in(0, \bar{k})$. We are about to show that, provided that the cost associated with green $R \& D$ is not too high, the stability conditions (5) are simultaneously verified by some admissible values of $m$ at least equal to one and at most equal to $n$. To this aim, define as (1) $m_{\mathrm{I}}$ the maximum value of $m$, such that internal stability holds, i.e., $\pi_{g}^{m}>\pi_{b}^{n-(m-1)}$, and (2) $m_{\mathrm{E}}$ the minimum value of $m$ above which external stability holds, i.e., $\pi_{b}^{n-m}>\pi_{g}^{m+1}$. The following lemma applies.

Lemma 2 There exists an admissible $\hat{k}>0$, such that any $k \in(0, \hat{k}]$ ensures $m_{\mathrm{I}}, m_{\mathrm{E}} \geq 1$.

Proof The first difference related to the internal stability shows that:

$$
\pi_{g}^{m}-\pi_{b}^{n-(m-1)}=\frac{n(t-c)[2(a-c)-(t-c)(2 m-n)]-k(1+n)^{2}}{(1+n)^{2}} \geq 0,
$$

if and only if

$$
m \leq m_{\mathrm{I}} \equiv \frac{n(t-c)[n(t-c)+2(a-c)]-k(1+n)^{2}}{2 n(t-c)^{2}} .
$$

In turn, $m_{\mathrm{I}} \geq 1$ for all $k \in(0, \bar{k}]$.

External stability requires:

$$
\pi_{b}^{n-m}-\pi_{g}^{m+1}=\frac{k(1+n)^{2}-n(t-c)[2(a-t)+(t-c)(n-2 m)]}{(1+n)^{2}} \geq 0,
$$

which holds for all:

$$
m \geq m_{\mathrm{E}} \equiv \frac{n(t-c)[2(a-t)+n(t-c)]-k(1+n)^{2}}{2 n(t-c)^{2}} .
$$

In turn, $m_{\mathrm{E}} \geq 1$ for all $k \in(0, \hat{k}]$, with:

$$
\widehat{k} \equiv \frac{n(t-c)[2(a+c-2 t)+n(t-c)]}{(n+1)^{2}} .
$$

Note that $\operatorname{sign}\{\hat{k}\}=\operatorname{sign}\{2(a+c-2 t)+n(t-c)\}$. A sufficient condition for $\widehat{k}>0$ is $a+c \geq 2 t$. If instead $a+c<2 t$ :

$$
\widehat{k}>0 \Leftrightarrow n>\frac{2(2 t-a-c)}{t-c},
$$




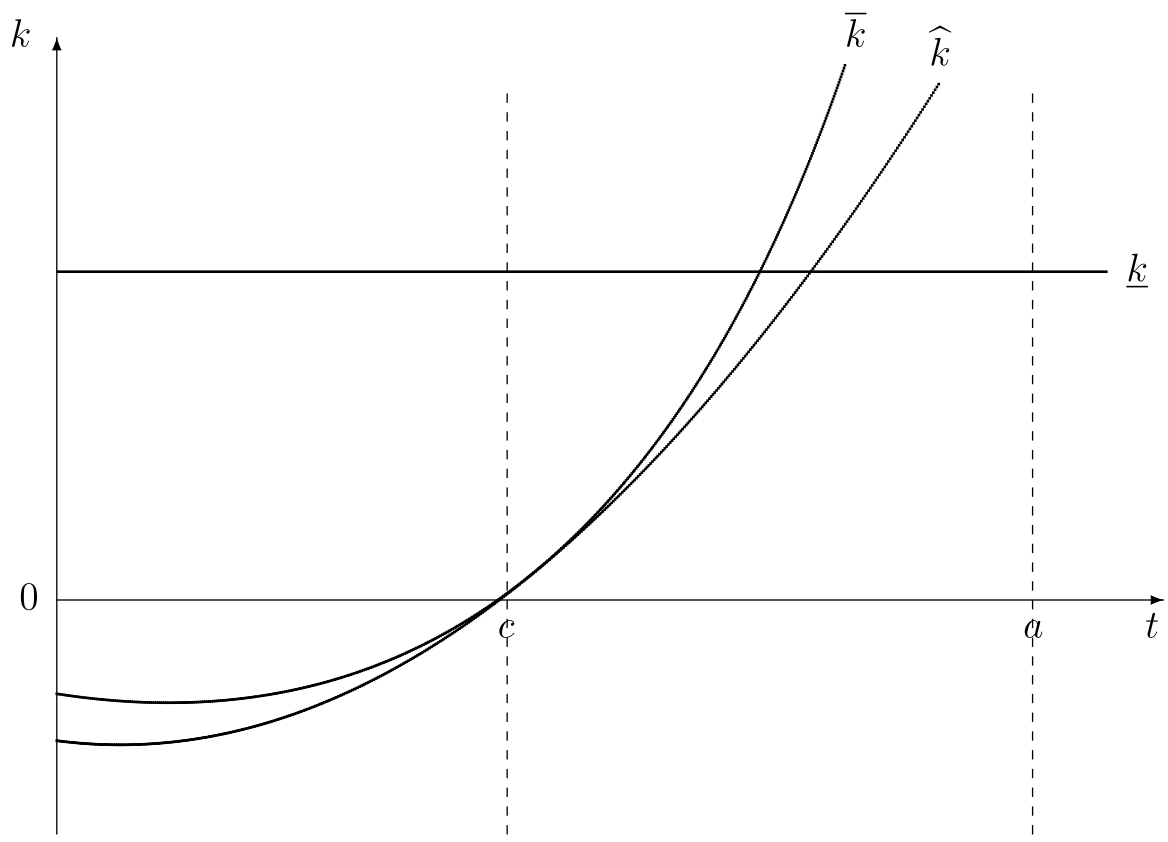

Fig. 2 Internal and external stability of the green coalition

with $(2 t-a-c) /(t-c)<1$ always, because $a>t$. Therefore, $\hat{k}$ is positive everywhere.

Now, observe that the difference between the two critical levels of cost $k$ is equal to:

$$
\bar{k}-\widehat{k}=\frac{2 n(t-c)^{2}}{(n+1)^{2}}>0 .
$$

This indeed implies that, if $k \in(0, \hat{k}]$, then $m_{\mathrm{I}}, m_{\mathrm{E}} \geq 1$. Adding up $\hat{k}$ to the picture, we obtain the graph in Fig. 2, where it appears that $\hat{k}$ becomes binding in place of $\bar{k}$.

This concludes the proof.

It is worth stressing that since $\bar{k}>\hat{k}$, what bites here is the highest admissible level of the R\&D cost below which the external stability requirement is met by a coalition of admissible size, i.e., at least a singleton. This prompts for a comparison between $m_{\mathrm{I}}$ and $m_{\mathrm{E}}$, because if $m_{\mathrm{E}}$ is higher than $m_{\mathrm{I}}$, then no stable green coalition may exist. A quick comparison between the two relevant expressions delivers:

Corollary 1 Take $k \in(0, \hat{k}]$, so that $m_{\mathrm{I}}, m_{\mathrm{E}} \geq 1$. In this range, $m_{\mathrm{I}}-m_{\mathrm{E}}=1$ everywhere.

Since $m$ must be an integer, Lemma 2 and Corollary 1 yield the following relevant result: 
Proposition 1 Take $k \in(0, \hat{k}]$, so that $m_{\mathrm{I}}, m_{\mathrm{E}} \geq 1$, with $m_{\mathrm{I}}-m_{\mathrm{E}}=1$. In this range, there exists a stable green coalition of size $m \in\left[m_{\mathrm{I}}, \min \left\{n, m_{\mathrm{E}}\right\}\right]$.

Figure 2 shows the result. Proposition 1 says that there exists an admissible partition of the parameter space (in particular, a range of values for $k$ ), wherein a green coalition is stable. Intuitively, the green coalition is unstable for high investment costs $k \in(\hat{k}, \bar{k})$.

Finally, notice that the size of the green coalition might even coincide with the entire population of firms. That is, at equilibrium, we might observe the arising of a grand green coalition. To check it out, one has to perform the analysis of the conditions under which this outcome will indeed obtain and characterise its welfare properties, to verify whether we may expect the whole industry to attain the win-win solution implied by the strong version of the $\mathrm{PH}$.

\section{Grand green coalition and social optimum}

In this section, we illustrate the conditions according to which the PH emerges in its strong version, and we determine the welfare properties of the grand coalition made up by $n$ green firms.

To begin with, consider that, since $m_{\mathrm{I}}-m_{\mathrm{E}}=1, n \in\left[m_{\mathrm{E}}, m_{\mathrm{I}}\right]$ is the necessary and sufficient condition to ensure that the grand coalition $m=n$ will indeed be the unique stable one. Now, let $a_{\mathrm{I}}$ be the lowest level of the choke price above which $m_{\mathrm{I}}>n$, and $a_{\mathrm{E}}$ be the highest level of the choke price below which $n>m_{\mathrm{E}}$, respectively. The following holds:

Proposition 2 For $k \in(0, \min \{\hat{k}, \tilde{k}\})$ and $a \in\left(a_{\mathrm{I}}, a_{\mathrm{E}}\right)$, the grand coalition consisting of $n$ green firms is stable.

Proof The comparison between $m_{\mathrm{I}}$ with $n$ yields:

$$
m_{\mathrm{I}}-n=\frac{a-c}{t-c}-\frac{n}{2}-\frac{k(1+n)^{2}}{2 n(t-c)^{2}} .
$$

This difference is positive for all:

$$
a>a_{\mathrm{I}} \equiv \frac{k(1+n)^{2}+n(t-c)[2 c+n(t-c)]}{2 n(t-c)^{2}}>0 .
$$

Then, comparing $n$ with $m_{\mathrm{E}}$, we obtain:

$$
n-m_{\mathrm{E}}=\frac{k(1+n)^{2}-n(t-c)[2(a-t)-n(t-c)]}{2 n(t-c)^{2}} .
$$




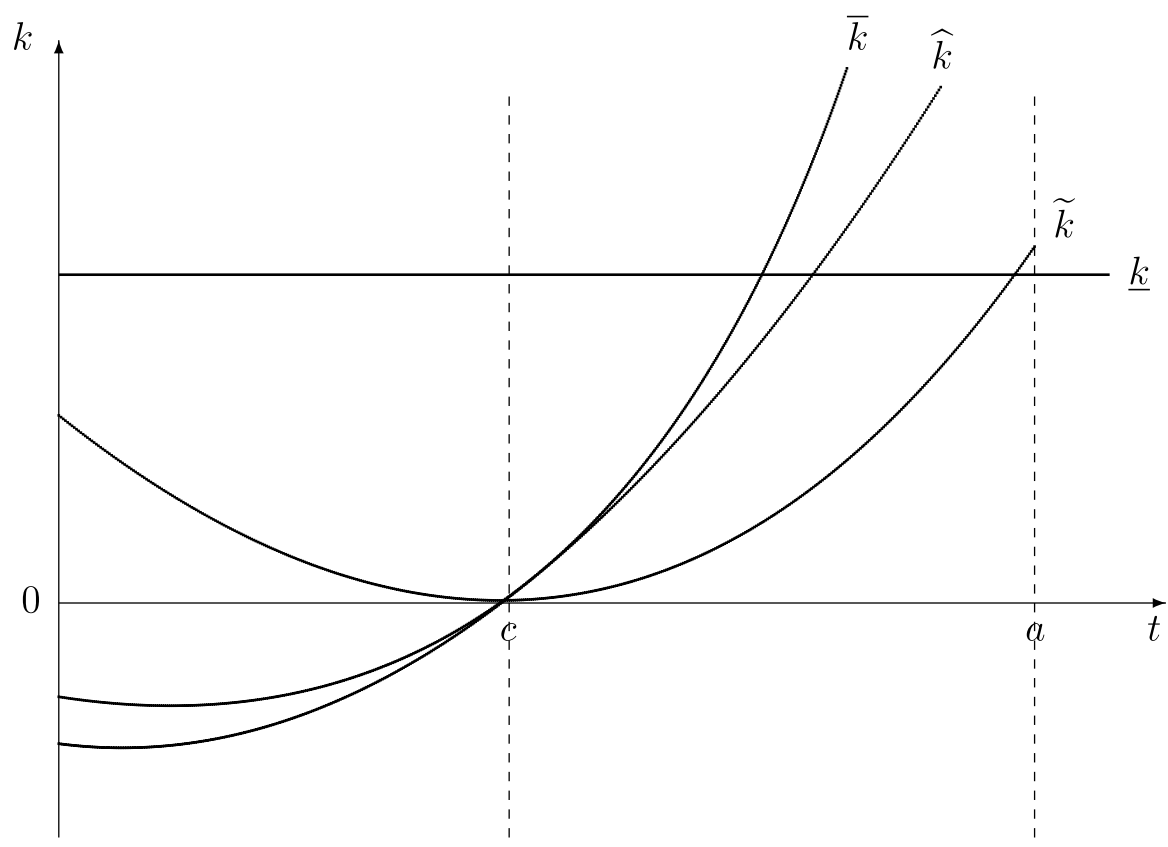

Fig. 3 Stability of the green grand coalition

A sufficient condition for the r.h.s. of (6) to be positive is $a \in\left(t, a_{\mathrm{E}}\right)$, with $a_{\mathrm{E}} \equiv[n(t-c)+2 t] / 2>t$. Finally, $a_{\mathrm{I}}<a_{\mathrm{E}}$ iff:

$$
\frac{2 n(t-c)-k(1+n)^{2}}{2 n(t-c)}>0,
$$

which is true for all $k \in(0, \tilde{k})$, where $\tilde{k} \equiv 2 n(t-c) /(1+n)^{2}$. Comparing $\tilde{k}$ against $\bar{k}$ and $\hat{k}$, one finds that $\bar{k}>\widetilde{k}$ everywhere, while $\hat{k}-\widetilde{k}$ has the same sign as $2(a-c)+(n-6)(t-c)$, which is surely positive for all $n \geq 6$, but may change sign if industry concentration is sufficiently high. The condition posed by $\widetilde{k}$ is more stringent than that implied by $\widehat{k}$, as depicted in Fig. 3 .

The foregoing analysis has been carried out identifying thresholds for $k$ below which (1) a green coalition of size $m$ is stable, and (2) the grand green coalition $m=n$ arises, possibly yielding a vindication of the $\mathrm{PH}$ in its strong formulation. Hence, one could say that the level of green R\&D costs has a pivotal role in shaping the behaviour of firms. This, true as it may be, would leave aside the role of emission taxation. Indeed, the critical thresholds for $k$ are defined in terms of $\{a, c, n, t\}$, i.e., the exogenous parameters and the policy instruments in the hands of the government. For any triple $\{a, c, n\}$ and any $k>0$, the policy maker can in fact manipulate $t$ so as to satisfy the two crucial conditions highlighted in Propositions 1 and 2, by fine-tuning the emission tax rate in such a way that $k<\widetilde{k}$, thus driving firms towards the generalised adoption of the green technology. 
This result is consistent with the empirical findings from the Progress report towards the EU's 2020 renewable energy goals (European Commission 2017), according to which cheaper technologies enables renewables to enter markets and spread in them.

We are left with one last task, which consists in checking whether a grand green coalition is indeed socially efficient industry configuration.

Proposition 3 The grand green coalition is socially efficient for all $k \in\left(0, \min \left\{\tilde{k}, k^{*}, \underline{k}\right\}\right)$, where:

$$
k^{*} \equiv \max \left\{0, \frac{a[t-c(n+2)]+c[n(n+2) t-c(n(n+1)-1)]}{(n+1)^{2}}\right\} .
$$

Proof The first order condition for the maximisation of social welfare with respect to $m$ yields:

$$
\frac{\partial S W}{\partial m}=\alpha m^{3}+\beta m^{2}+\gamma m+\delta=0
$$

where

$$
\begin{aligned}
\alpha= & 2 v(t-c)^{2}, \\
\beta= & -3 v(t-c)[a-c n+t(n-1)], \\
\gamma= & -2 c t(2+n)+a^{2} v-2 c n v[2 a+t(n-2)] \\
& +t[t+v(a(4 n-2)+t+t n(n-4))]+c^{2}[3+n(n v+2)], \\
\delta= & k-c^{2}(1+n)^{2}-a^{2} n v+c n t(2+n-n v)+n\left[k(2+n)+t^{2}((n-1)-1)\right] \\
& +a\left[c\left(2+n+n^{2} v\right)-t(n v(n-2)+1)\right] .
\end{aligned}
$$

We have to verify whether there exists an admissible subset of the parameter space $\{a, c, k, n, t\}$ where, at $m=n,(1) \partial \mathrm{SW} / \partial m \geq 0$, (2) the individual equilibrium profits of a green firm are positive, i.e., $\pi_{g}^{m=n}>0$; and (3) conditions (5) for internal and external stability are simultaneously satisfied.

By fixing $m=n$, we may rewrite (7) as follows:

$$
\left.\frac{\partial \mathrm{SW}}{\partial m}\right|_{m=n}=\frac{t[a+c n(2+n)]-c^{2}\left(n^{2}+n-1\right)-a c(2+n)-k(1+n)^{2}}{(1+n)^{2}} \geq 0,
$$

for all

$$
t \geq t^{*} \equiv \frac{c^{2}\left(n^{2}+n-1\right)+a c(2+n)+k(1+n)^{2}}{a+c n(2+n)},
$$

or, equivalently, for all 


$$
k \leq k^{*} \equiv \frac{a[t-c(n+2)]+c[n(n+2) t-c(n(n+1)-1)]}{(n+1)^{2}},
$$

whenever $k^{*}$ is positive. This critical level of $k$ must be evaluated against $\hat{k}$ and $\widetilde{k}^{14}$ This exercise reveals that $\hat{k}>k^{*}$ everywhere, while $\widetilde{k}>\widehat{k} \Leftrightarrow t>c$, and:

$$
\tilde{k}>k^{*} \Leftrightarrow t>\frac{a+n c(n+6)+\sqrt{a[1-2 c n(3 n+2)]+c^{2} n\left[n^{2}(n+4)+4(3 n+2)\right]}}{4 n} .
$$

Consider now that the profit function in equilibrium is equal to:

$$
\pi_{g}^{m=n}=\frac{(a-c)^{2}}{(1+n)^{2}}-k>0 \quad \forall k<\underline{k} \equiv \frac{(a-c)^{2}}{(1+n)^{2}},
$$

and

$$
\begin{aligned}
& \underline{k}>\widetilde{k} \quad \forall t \in\left(c, \frac{2 c n+(a-c) \sqrt{2 n}}{2 n}\right), \\
& \underline{k} \leq \widetilde{k} \quad \forall t \in\left[\frac{2 c n+(a-c) \sqrt{2 n}}{2 n}, a\right) .
\end{aligned}
$$

For any triple $\{a, c, n\}$, the critical levels $\left\{\underline{k}, \hat{k}, \widetilde{k}, k^{*}\right\}$ can be drawn in the space $(t, k)$.

Figure 4 shows the results of Proposition 3. The starred area above the horizontal axis, below the lower envelope of $\left\{\widetilde{k}, k^{*}, \underline{k}\right\}$ and such that $t \in(c, a)$, identifies the region we are looking for, in which the grand green coalition $m=n$ is socially efficient and is indeed delivered by firms' incentives. That is, the starred area is where the strong version of the $\mathrm{PH}$ obtains and delivers a win-win solution. The result is intuitive: the grand green coalition is socially efficient if the investment cost to implement the clean technology is sufficiently low.

The last step consists in looking at the position of the socially efficient tax rate in the graph appearing in Fig. 4, with a view to verifying whether the tax rate maximising the ex ante level of social welfare for a generic industry configuration $m \leq n$ can indeed drive the industry to the win-win solution. The maximisation of (1) w.r.t. $t$ is attained at ${ }^{15}$ :

$$
t_{\mathrm{SW}}=\frac{(a+c m)(n-m)(m+1) v-a-c m(n+2)}{(n-m)\left[(m+1)^{2} v+1\right]},
$$

\footnotetext{
$\overline{14}$ Recalling that $\bar{k}>\hat{k}$ always, $\bar{k}$ can be disregarded.

15 It is worth stressing that $t_{\mathrm{SW}}$ may either exceed the marginal environmental damage or fall short of it, as we know from Simpson (1995): if the damage function $S$ is not too steep, the regulator may typically soften the tax with a view to preserving consumer surplus and industry profits.
} 


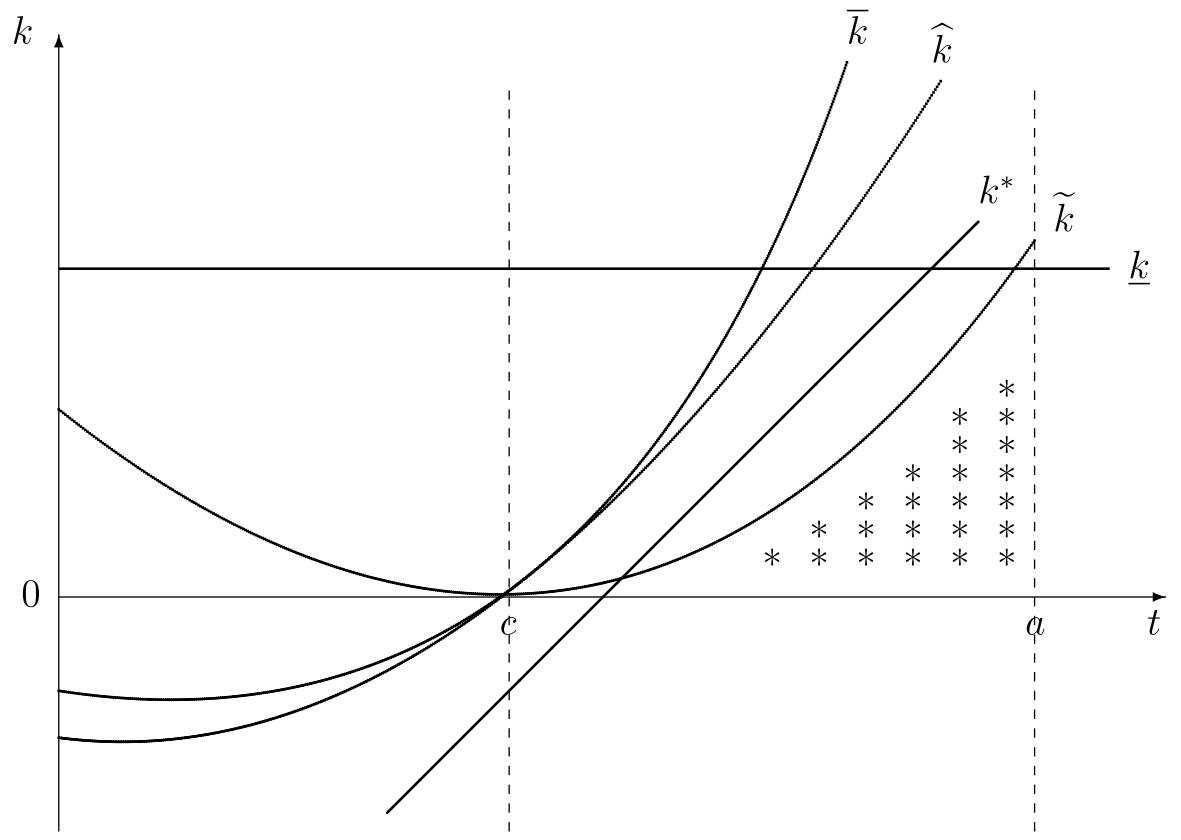

Fig. 4 The win-win solution

and this must be compared to the tax rate which drives $k^{*}$ to zero: ${ }^{16}$

$$
\left.t\right|_{k^{*}=0}=\frac{[a(n+2)+c(n(n+1)-1)] c}{a+c n(n+2) .}
$$

This yields:

$$
t_{\mathrm{SW}}-\left.t\right|_{k^{*}=0}=\frac{\Lambda-\Phi}{(n-m)\left[(m+1)^{2} v+1\right][a+c n(n+2)]}
$$

in which

$$
\begin{aligned}
& \Lambda \equiv(a-c)(n-m)(m+1)[a+c((n-m)(n+1)-1)] v>0 \\
& \Phi \equiv a[a+2 c n(n+2)]+c^{2}\left[m(n+1)^{2}+n(n(n+1)-1)\right] .
\end{aligned}
$$

Accordingly, $t_{\mathrm{SW}}>\left.t\right|_{k^{*}=0}$ for all:

$$
v>\frac{a[a+2 c n(n+2)]+c^{2}\left[m(n+1)^{2}+n(n(n+1)-1)\right]}{(a-c)(n-m)(m+1)[a+c((n-m)(n+1)-1)]} .
$$

This exercise proves the following result:

$\overline{16 \text { It can be easily checked that } t_{\mathrm{SW}}}$ is always lower than $a$ : 
Corollary 2 If the environmental damage is sufficiently steep, then the socially efficient emission tax tailored for an initial industry configuration $(m, n)$ indeed delivers the win-win solution.

This amounts to saying that, what may look, prima facie, the socially efficient tax rate in a situation in which only $m$ of the $n$ firms in the industry are green, turns out to be the driver of the Porter hypothesis in its strong formulation. It is worth stressing that this happens in scenarios where the externality increases in industry output at a high rate.

\section{Extensions}

The baseline results can be extended in several directions. Here, we explore the most relevant cases by looking first at an alternative policy like a subsidy to implement the green technology. Second, we investigate a framework where firms compete in prices. Third, we analyse a green $R \& D$ process with the explicit introduction of a cost-reducing R\&D activity of the green firms. Finally, to make the results even more robust, we extend the stability analysis to the case of either horizontal differentiation, isoelastic demand or quadratic costs of green production.

In each extension, we follow the procedure developed in the baseline analysis when it is possible analytically. Interestingly, the intuition of the results is similar to the baseline setting in all cases, making the insights of the original model very robust.

\subsection{Subsidising green innovation}

In this section, we assume that the government adopts a different policy. Instead of taxing the brown firms, it subsidises each unit of output of green firms. Therefore, the profit of a green firm is $\pi_{g \mathrm{~s}}=(p+s-c) q_{g}-k$, while that of a brown firm is $\pi_{b \mathrm{~s}}=p q_{b}$, where subscript s stands for "subsidy". Assuming $s>c$ ensures that there exists an incentive to choose the green strategy. In turn, social welfare is now:

$$
\mathrm{SW}_{\mathrm{s}}=\sum_{g=1}^{m} \pi_{g \mathrm{~s}}+\sum_{b=m+1}^{n} \pi_{b \mathrm{~s}}+C S_{\mathrm{s}}-(1+\lambda) s Q_{\mathrm{s}}-S_{s} .
$$

In Eq. (8), $(1+\lambda) s Q_{\mathrm{s}}$ represents the cost of the subsidy, where $\lambda \in(0,1)$ represents the shadow cost of public funds (see Laffont and Tirole 1986; Matsumura and Tomaru 2013; Sato and Matsumura 2017, inter alia). Equilibrium quantities are:

$$
q_{g \mathrm{~s}}^{m}=\frac{a+(s-c)(n+1-m)}{n+1} ; q_{b \mathrm{~s}}^{n-m}=\frac{a-m(s-c)}{n+1},
$$

while profits are: 


$$
\pi_{g s}^{m}=\frac{[a+(c-s)(m-n-1)]^{2}}{(n+1)^{2}}-k ; \pi_{b s}^{n-m}=\frac{[a-m(s-c)]^{2}}{(n+1)^{2}} .
$$

The condition for the grand green coalition to be viable is $k>\underline{k} v \equiv(a+s-c)^{2} /(n+1)^{2}$, while a grand brown coalition is stable if $k<\bar{k}_{\mathrm{s}}$, where:

$$
\bar{k}_{\mathrm{s}} \equiv \frac{n(s-c)[n(s-c)+2 a]}{(n+1)^{2}} .
$$

Profits of a deviating green and brown firm are, respectively:

$$
\pi_{b s}^{n-m+1}=\frac{[a-(m-1)(s-c)]^{2}}{(n+1)^{2}} ; \pi_{g s}^{m+1}=\frac{[a-(s-c)(m-n)]^{2}}{(n+1)^{2}}-k .
$$

The condition for internal stability, $\pi_{g \mathrm{~s}}^{m}-\pi_{b \mathrm{~s}}^{n-(m-1)} \geq 0$, holds for $m \leq m_{\mathrm{Is}}$, where:

$$
m_{\mathrm{Is}} \equiv \frac{n(s-c)[(n+2)(s-c)+2 a]-k(n+1)^{2}}{2 n(s-c)^{2}} .
$$

The condition for external stability instead, $\pi_{b \mathrm{~s}}^{n-m} \geq \pi_{g \mathrm{~s}}^{m+1}$, holds for $m \geq m_{\mathrm{Es}}$, where:

$$
m_{\mathrm{Es}} \equiv \frac{n(s-c)[n(s-c)+2 a]-k(n+1)^{2}}{2 n(s-c)^{2}}
$$

and $m_{\mathrm{Es}}$ is greater than 1 for $k<\widehat{k}_{\mathrm{s}}$, where:

$$
\widehat{k}_{\mathrm{s}} \equiv \frac{n(s-c)[(n-2)(s-c)+2 a]}{(n+1)^{2}} .
$$

In addition, $\bar{k}_{\mathrm{s}}-\widehat{k}_{\mathrm{s}}=2 n(s-c)^{2} /(n+1)^{2}>0$. Similar to the baseline model, the range in which the coalition is stable exists, since $m_{\mathrm{Is}}-m_{\mathrm{Es}}=1$.

We now check the conditions under which a grand green coalition is stable. Denote as $a_{\mathrm{Is}}$ the lowest level of the choke price above which $m_{\mathrm{Is}}>n$, that is:

$$
\begin{aligned}
& m_{\mathrm{Is}}-n=\frac{1}{2}\left[\frac{2 a}{s-c}-\frac{k(n+1)^{2}}{n(c-s)^{2}}-n+2\right]>0 \Leftrightarrow \\
& a>a_{\mathrm{Is}} \equiv \frac{(n-2) n(s-c)^{2}+k(n+1)^{2}}{2 n(s-c)} .
\end{aligned}
$$

We denote next $a_{\mathrm{Es}}$ as the highest level of the choke price below which $n>m_{\mathrm{Es}}$, that is:

$$
\begin{aligned}
& m_{\mathrm{Es}}-n=\frac{1}{2}\left[\frac{k(n+1)^{2}}{n(s-c)^{2}}+n-\frac{2 a}{s-c}\right]>0 \Leftrightarrow \\
& a>a_{\mathrm{Es}} \equiv \frac{n^{2}(s-c)^{2}+k(n+1)^{2}}{2 n(s-c)} .
\end{aligned}
$$


Finally, $a_{\mathrm{Es}}-a_{\mathrm{Is}}=s-c>0$. Differentiating social welfare $\mathrm{SW}_{\mathrm{s}}$, and fixing $m=n$, we get $\left.\frac{\partial \mathrm{SW}_{\mathrm{s}}}{\partial m}\right|_{m=n}=0$ for all $k \leq k_{\mathrm{s}}^{*}$, whenever $k_{\mathrm{s}}^{*}$ is positive, where $\left.\frac{\partial \mathrm{SW}_{\mathrm{s}}}{\partial m}\right|_{m=n}$ and $k_{\mathrm{s}}^{*}$ are formally derived in the appendix. Finally, $\hat{k}>k_{\mathrm{s}}^{*}$ for $a>a_{\mathrm{s}}^{*}$, where:

$$
a v^{*} \equiv \frac{(n-1)(s-c)[2 c n+c+s(\lambda+(\lambda-1) n)]}{s(\lambda+(\lambda+2) n)-s-c(n-2)} .
$$

Differentiating $k_{\mathrm{s}}^{*}$ with respect to $\lambda$, we get:

$$
\frac{\partial k_{\mathrm{s}}^{*}}{\partial \lambda}=-\frac{s[a-(n-1)(s-c)]}{n+1}<0,
$$

for $a>\widehat{a}_{\mathrm{s}} \equiv(n-1)(s-c)$. Therefore, an increase in the cost of public funding has ambiguous effects on the efficiency of the grand green coalition, based on the level of the choke price: if $a$ is sufficiently high, an increase in the cost of public funding decreases the threshold $k_{\mathrm{s}}^{*}$ under which the grand green coalition is socially efficient.

We conclude the section by investigating the level of socially optimal subsidy, and we compare it with the socially optimal tax rate. Differentiating $\mathrm{SW}_{\mathrm{s}}$ with respect to $s$ yields $\frac{\partial \mathrm{SW}_{\mathrm{s}}}{\partial s}=0$ for $s=s_{\mathrm{s}}^{*}$, where $\frac{\partial \mathrm{SW}_{\mathrm{s}}}{\partial s}=0$ and $s_{\mathrm{s}}^{*}$ are formally derived in the appendix.

We can now compare the welfare levels alternatively generated by the socially optimal subsidy $s_{\mathrm{SW}}$ and the optimal tax rate $t_{\mathrm{SW}}$. It is worth stressing that, for any $\lambda>0$, the weight of total subsidisation in (8) exceeds the weight of tax income $T$ in (1). ${ }^{17}$ This implies that, strictly speaking, the alternative cases of taxing brown firms' emissions and subsidising green firms' production are comparable only for $\lambda=0$. In addition, to fix ideas, we focus on the case where all firms but one have a green production, i.e., $m=n-1$, which gives $\mathrm{SW}\left(t_{\mathrm{SW}}\right)-\left.\mathrm{SW}_{\mathrm{S}}\left(s_{\mathrm{SW}}\right)\right|_{\lambda=0, m=n-1}>0$, for $n>n_{\mathrm{s}}$, where:

$$
n_{\mathrm{s}} \equiv \frac{\left(a^{2} v(v+1)-2 a c(v+1)^{2}+c^{2}(v(v+2)+5)\right)^{1 / 2}}{c(1-v)} .
$$

The results are intuitive. The cost of subsidy is too high when the number of firms receiving the subsidy is too large.

\subsection{Price competition}

In this section, we investigate whether the baseline results are robust to a setting with horizontal differentiation and Bertrand competition. The focus is on whether the results proposed int the baseline model of Sect. 2 survives in the case of price competition. In this setting, the demand is:

\footnotetext{
${ }^{17}$ Indeed, empirical evidence shows that $\lambda$ is usually positive, although smaller than 1 . See Laffont (2005), and Kleven and Kreiner (2006), inter alia.
} 


$$
Q_{b}=\frac{a n}{\gamma(n-1)+1}-\frac{m p_{g}}{\gamma(n-1)+1}-\frac{(n-m) p_{b}}{\gamma(n-1)+1},
$$

where subscript B stands for "Bertrand". To fix ideas, in what follows we set $\gamma=1 / 2$ to ensure a certain degree of complementarity among products. ${ }^{18}$ Price competition yields:

$$
\begin{aligned}
p_{g \mathrm{~B}}^{m} & =\frac{a(2 n+1)+c n(m+n+1)+n t(n-m)}{(n+1)(2 n+1)}, \\
p_{b \mathrm{~B}}^{n-m} & =\frac{a(2 n+1)+n[(2 n+1)-m(t-c)]}{(n+1)(2 n+1)} .
\end{aligned}
$$

Profits are:

$$
\begin{aligned}
\pi_{g \mathrm{~B}}^{m} & =\frac{2 n[n(c(n-m+2)+t(m-n))+c-a(2 n+1)]^{2}}{(n+1)^{3}(2 n+1)^{2}}-k, \\
\pi_{b \mathrm{~B}}^{n-m} & =\frac{2 n[2 a n+a+c m n-t((m+2) n+1)]^{2}}{(n+1)^{3}(2 n+1)^{2}} .
\end{aligned}
$$

The condition for the grand green coalition to be viable is $k \in\left[0, \underline{k}_{b}\right)$, where $\underline{k}_{b}=2 n(a-c)^{2} /(n+1)^{3}$. Conversely, the grand brown coalition is unstable for all $\bar{k} \in\left(0, \bar{k}_{b}\right)$, where:

$$
\bar{k}_{b} \equiv \frac{2 n\left(n^{2}+n+1\right)(t-c)[2 a(2 n+1)-n(c n+c-n t+3 t)-c-t]}{(n+1)^{3}(2 n+1)^{2}} .
$$

To determine the stability of the coalition, we derive profits of a deviating green firm and a deviating brown firm, respectively:

$$
\begin{aligned}
\pi_{b \mathrm{~B}}^{n-m+1} & =\frac{2 n[a(2 n+1)+c n(m-1)-t(m n+n+1)]^{2}}{(n+1)^{3}(2 n+1)^{2}}, \\
\pi_{g \mathrm{~B}}^{m+1} & =\frac{2 n[n(c(-m+n+1)+t(m-n+1))+c-a(2 n+1)]^{2}}{(n+1)^{3}(2 n+1)^{2}}-k .
\end{aligned}
$$

The condition for internal stability, $\pi_{g \mathrm{~B}}^{m}-\pi_{b \mathrm{~B}}^{n-(m-1)} \geq 0$, holds for $m<m_{\mathrm{IB}}$, where:

$$
m_{\mathrm{IB}} \equiv \frac{2 n\left(n^{2}+n+1\right)\left(c-t[)-2 a(2 n+1)+c\left(n^{2}+3 n+1\right)+\left(-n^{2}+n+1\right) t\right]-k(n+1)^{3}(2 n+1)^{2}}{4 n^{2}\left(n^{2}+n+1\right)(c-t)^{2}},
$$

where $m_{\mathrm{IB}}>1$ for $k \in\left(0, \bar{k}_{b}\right)$. The condition for external stability instead, $\pi_{b \mathrm{~B}}^{n-m} \geq \pi_{g \mathrm{~B}}^{m+1}$, holds for $m<m_{\mathrm{EB}}$, where:

18 The effect on the substitutability or complementarity of the goods is instead discussed with further details in Sect. 5.4. 


$$
m_{\mathrm{EB}} \equiv \frac{2 n\left(n^{2}+n+1\right)(c-t)\left[-2 a(2 n+1)+c\left(n^{2}+n+1\right)+n^{2}(-t)+3 n t+t\right]-k(n+1)^{3}(2 n+1)^{2}}{4 n^{2}\left(n^{2}+n+1\right)(c-t)^{2}},
$$

where $m_{\mathrm{EB}}>1$ for $k \in\left(0, \widehat{k}_{b}\right)$, where

$$
\hat{k}_{b} \equiv \frac{2 n\left(n^{2}+n+1\right)(c-t)[n(c(n-1)-(n-5) t)-2 a(2 n+1)+c+t]}{(n+1)^{3}(2 n+1)^{2}} .
$$

Like in the baseline model, $m_{\mathrm{IB}}-m_{\mathrm{EB}}=1$ whenever $k \in\left(0, \hat{k}_{b}\right)$.

Condition $n \in\left[m_{\mathrm{EB}}, m_{\mathrm{IB}}\right]$ is again the necessary and sufficient condition to ensure that the grand coalition $m=n$ is the unique stable one. We denote as $a_{\mathrm{IB}}$ the lowest level of the choke price above which $m_{\mathrm{IB}}>n$, and $a_{\mathrm{EB}}$ as the highest level of the choke price below which $n>m_{\mathrm{EB}}$, where $a_{\mathrm{IB}}$ and $a_{\mathrm{EB}}$ are formally derived in the appendix. Finally, $a_{\mathrm{EB}}-a_{\mathrm{IB}}=n(t-c) /(2 n+1)>0$, so that the range of existence of the grand green coalition always exists.

We conclude the section by verifying whether a grand green coalition is an efficient industry configuration even with Bertrand competition. Differentiating social welfare, denoted as $\mathrm{SW}_{b}$, and fixing $m=n$, we get $\left.\frac{\partial \mathrm{SW}_{b}}{\partial m}\right|_{m=n} \geq 0$ for all $k \leq k_{b}^{*}$, whenever $k_{b}^{*}$ is positive, and where $\left.\frac{\partial \mathrm{SW}_{b}}{\partial m}\right|_{m=n}$ and $k_{b}^{*}$ are formally derived in the appendix. Finally, $\hat{k}>k^{*}$ for $a>a_{b}^{*}$, whose expression is relegated in the appendix. We confirm that a market with price competition and a certain degree of substitutability have similar stability conditions compared to the baseline setting. In particular, all the results proposed in this section confirm that the stability of the grand green coalition and the socially efficient solution is compatible with both price and quantity strategies in the market.

\subsection{Green R\&D}

In this section, we explicitly introduce a cost-reducing $R \& D$ activity by green firms. This structure is typical in the industrial organization literature, and aims to model the real effect of innovation in green technology. We stipulate that the green firm exerts an explicit R\&D effort, denoted as $r$, to make the green product more competitive. The profit function of a green firm is now:

$$
\pi_{g}=p q_{g}-\left(c-r_{g}\right) q_{g}-\frac{\theta r_{g}^{2}}{2}-k, \theta>0,
$$

where $c-r_{g}$ represents the fact that R\&D effort decreases the unit cost of the green technology, while $\theta r_{g}^{2} / 2$ represents the fixed R\&D cost. To ease the exposition and limit the number of parameters, we set $\theta=3 / 4$ which ensures that the above objective function is well defined and the maximisation process due to the concavity condition is ensured. In this case, green firms compete by simultaneously choosing their optimal quantity and the R\&D effort, while brown firms only choose their 
quantities. The market equilibrium is now represented by the following output levels and research effort:

$$
\begin{aligned}
q_{g \mathrm{R}}^{m} & =\frac{3[a-c(1+n-m)+(n-m) t]}{4 m-1-n}, \\
r_{g \mathrm{R}}^{m} & =\frac{4[a-c(1+n-m)+(n-m) t]}{4 m-1-n}, \\
q_{b \mathrm{R}}^{n-m} & =\frac{a-3 c m+(3 m-1) t}{4 m-1-n},
\end{aligned}
$$

where subscript R stands for "R\&D”. The profits of a green firm are:

$$
\pi_{g \mathrm{R}}^{m}=\frac{3[a-c(1+n-m)+(n-m) t]^{2}}{(4 m-1-n)^{2}}-k,
$$

while the profits of a brown firm are:

$$
\pi_{b \mathrm{R}}^{n-m}=\frac{[a-3 c m+(3 m-1) t]^{2}}{(4 m-1-n)^{2}} .
$$

Following the procedure of the baseline model, the viability condition for the grand green coalition is $k \in\left[0, \underline{R}_{\mathrm{R}}\right)$, with $\underline{k}_{\mathrm{R}}=3(a-c)^{2} /(3 n-1)^{2}$. Conversely, the grand brown coalition is unstable for all $k \in\left(0, \bar{k}_{\mathrm{R}}\right)$, where:

$$
\begin{aligned}
\bar{k}_{\mathrm{R}} \equiv & \frac{a\left[2 a(n(n+6)-3)-3 c n(n+1)^{2}+2(n(n(3 n+4)-9)+6) t\right]}{(n-3)^{2}(n+1)^{2}} \\
& +\frac{3 c(n+1)^{2} n[c n-2(n-1) n t]+\left(n\left(3 n^{3}-7 n+6\right)-6\right) t^{2}}{(n-3)^{2}(n+1)^{2}} .
\end{aligned}
$$

To determine the stability of the coalition, we derive profits of a deviating green firm and a deviating brown firm, respectively:

$$
\pi_{b \mathrm{R}}^{n-m+1}=\frac{[a-3 c(m-1)+(3 m-4) t]^{2}}{(4 m-n-5)^{2}} ; \pi_{g \mathrm{R}}^{m+1}=\frac{3[a+(t-c)(n-m)-t]^{2}}{(4 m-n+3)^{2}}-k .
$$

Notice that, unlike the baseline model, the condition such that $\pi_{g \mathrm{R}}^{m}=\pi_{b \mathrm{R}}^{n-(m-1)}$ can be established w.r.t. $k$. The condition for internal stability, $\pi_{g \mathrm{R}}^{m}-\pi_{b \mathrm{R}}^{n-(m-1)} \geq 0$, holds for $k \leq k_{\mathrm{IR}}$, while the condition for external stability instead, $\pi_{b \mathrm{R}}^{n-m} \geq \pi_{g \mathrm{R}}^{m+1}$, holds for $k \geq k_{\mathrm{ER}}$, where $k_{\mathrm{IR}}>k_{\mathrm{ER}} \Leftrightarrow t>\max \left\{0, \widehat{t}_{\mathrm{R}}\right\}$. The formal derivation of $k_{\mathrm{IR}}, k_{\mathrm{ER}}$ and $\widehat{t}_{\mathrm{R}}$ can be found in the appendix. It follows that a grand green coalition holds for $t>\max \left\{0,\left.\hat{t}_{\mathrm{R}}\right|_{m=n}\right\}$.

Having outlined the conditions for stability and for the existence of a grand green coalition, we are now able to check whether the grand green coalition may be indeed 
optimal. The explicit analysis of green $R \& D$ allows us to model pollution abatement as a function of the R\&D effort. Differentiating social welfare, denoted here as $\mathrm{SW}_{\mathrm{R}}$, with respect to $m$ and then fixing $m=n$, we get $\left.\frac{\partial \mathrm{SW}_{\mathrm{R}}}{\partial m}\right|_{m=n} \geq 0$ for all $t \geq t_{\mathrm{R}}^{*}$, where both $\frac{\partial \mathrm{SW}_{\mathrm{R}}}{\partial m}$ and $t_{\mathrm{R}}^{*}$ are formally derived in the appendix. It follows that the grand green coalition is socially efficient for all $t \geq \max \left\{\hat{t}_{\mathrm{R}}, t_{R}^{*}\right\}$. Therefore, our analysis in this section is robust to the introduction of explicit $\mathrm{R} \& \mathrm{D}$ effort.

\subsection{Horizontal differentiation}

In this section, we explore the case where goods produced by a type of firm are differentiated to goods produced by the other firm type. The inverse demand function of a green or brown firm are, respectively:

$$
p_{g \mathrm{~h}}=a-m q_{g}-\gamma q_{b}(n-m) ; p_{b \mathrm{~h}}=a-q_{b}(n-m)-\gamma m q_{g},
$$

where $\gamma \in(-1,1]$ and subscript $\mathrm{h}$ stands for "horizontal differentiation". Equilibrium quantities are:

$$
\begin{aligned}
& q_{g \mathrm{~h}}=\frac{(a-c)(n+1-m)-\gamma(a-t)(n-m)}{\left(1-\gamma^{2}\right) m(n-m)+n+1}, \\
& q_{b \mathrm{~h}}=\frac{(m+1)(a-t)-\gamma m(a-c)}{\left(1-\gamma^{2}\right) m(n-m)+n+1},
\end{aligned}
$$

while equilibrium profits are:

$$
\begin{aligned}
\pi_{g h}^{m} & =\frac{[(a-c)(n+1-m)-\gamma(a-t)(n-m)]^{2}}{\left[\left(1-\gamma^{2}\right) m(n-m)+n+1\right]^{2}}-k, \\
\pi_{b h}^{n-m} & =\frac{[(m+1)(a-t)-\gamma m(a-c)]^{2}}{\left[\left(1-\gamma^{2}\right) m(n-m)+n+1\right]^{2}},
\end{aligned}
$$

respectively.

The condition for which the grand green coalition is viable is $k \in\left[0, \underline{k}_{\mathrm{h}}\right)$, where $\underline{k}_{\mathrm{h}}=(a-c)^{2} /(n+1)^{2}$, while the green-brown coalition is stable for $k<\bar{k}_{\mathrm{h}}$, where:

$$
\bar{k}_{\mathrm{h}} \equiv \frac{[n(c-a)+\gamma(n-1)(a-t)]^{2}}{\left(\gamma^{2}(n-1)-2 n\right)^{2}}-\frac{(a-t)^{2}}{(n+1)^{2}} .
$$

The profits of a deviating green and brown firm are, respectively:

$$
\begin{aligned}
\pi_{b \mathrm{~h}}^{n-m+1} & =\frac{[\gamma(m-1)(a-c)+m(t-a)]^{2}}{\left[\gamma^{2}(m-1)(m-n-1)+m(-m+n+2)\right]^{2}}, \\
\pi_{g \mathrm{~h}}^{m+1} & =\frac{[(a-c)(n-m)+\gamma(a-t)(m-n+1)]^{2}}{\left[\gamma^{2}(m+1)(m-n+1)+(m+2)(n-m)\right]^{2}}-k .
\end{aligned}
$$




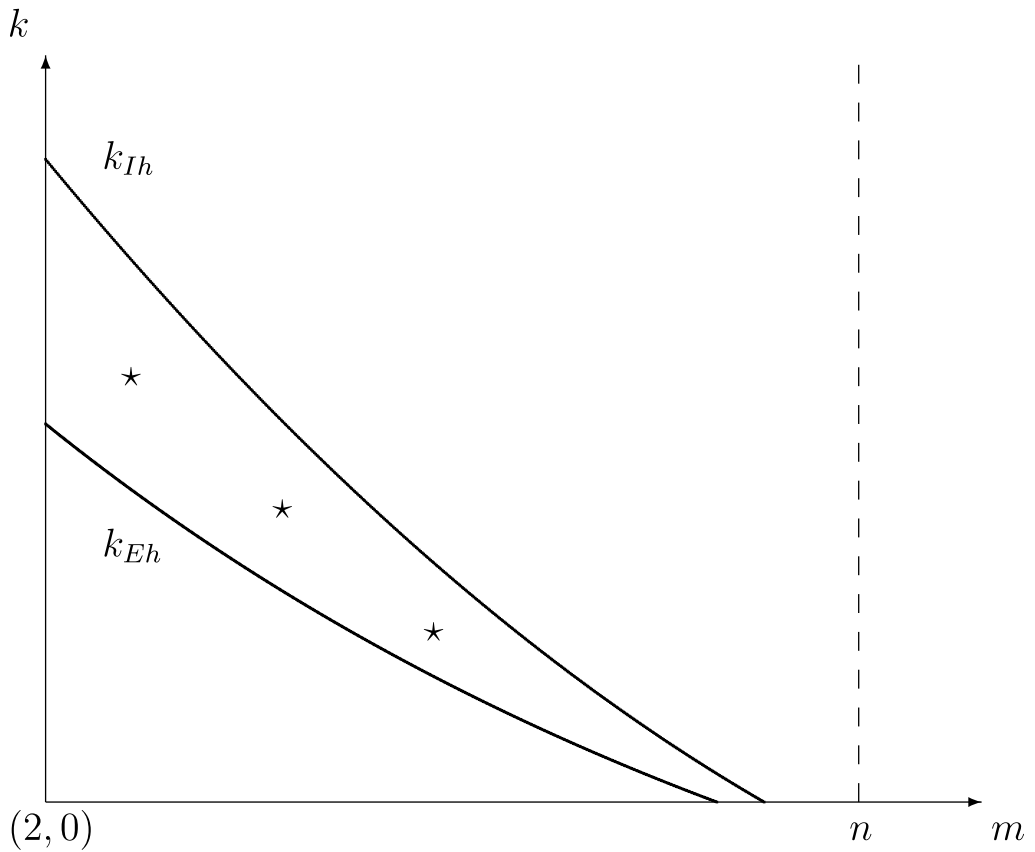

Fig. 5 The stability region with horizontal differentiation

The condition for internal stability, $\pi_{g \mathrm{~h}}^{n-m}-\pi_{b \mathrm{~h}}^{n-m+1} \geq 0$, holds for $k \leq k_{\mathrm{Ih}}$, while the condition for external stability instead, $\pi_{b \mathrm{~h}}^{n-m} \geq \pi_{g \mathrm{~h}}^{m+1}$, holds for $k \geq k_{\mathrm{Eh}}$, where $k_{\mathrm{Ih}}$ and $k_{\mathrm{Eh}}$ are formally defined in the appendix. Note that $k_{\mathrm{Ih}}>k_{\mathrm{Eh}}$ when both are positive. Figure 5 shows the results. The starred area between $k_{\mathrm{Ih}}$ and $k_{\mathrm{Eh}}$ is that wherein the stability condition is satisfied. Both the critical thresholds of $k$ become nil at some $m<n$ for all $\gamma \in[-1,1)$, and the intersections between $k_{\mathrm{Jh}}, \mathrm{J}=\mathrm{E}$, I, and the horizontal axis move rightwards as $\gamma$ increase towards one.

The special case in which firms sell full substitutes, which brings us back to the initial setup, can be briefly given some additional attention. As soon as $\gamma=1$, the expressions of the two critical investment levels simplify as follows:

$$
\begin{aligned}
& k_{\mathrm{Eh}}^{\gamma \rightarrow 1}=\frac{n(t-c)[2(a-t)-(t-c)(2 m-n)]}{(n+1)^{2}} \\
& k_{\mathrm{Ih}}^{\gamma \rightarrow 1}=\frac{n(t-c)[2(a-c)-(t-c)(2 m-n)]}{(n+1)^{2}},
\end{aligned}
$$

so that $k_{\mathrm{Ih}}^{\gamma \rightarrow 1}-k_{\mathrm{Eh}}^{\gamma \rightarrow 1}=2 n(t-c)^{2} /(n+1)^{2}>0$ for all $t>c$. Now, observe that $k_{\mathrm{Eh}}^{\gamma \rightarrow 1}=0$ in $c=t$ (but this, which would be true also for $k_{\mathrm{Ih}}^{\gamma \rightarrow 1}$, is excluded by assumption from the very outset) and $m=[2 a-c n+t(n-2)] /[2(t-c)]$, which, in turn, is strictly increasing in $n$ and must be at most equal to $n$. This happens at $\hat{n}=2(a-t) /(t-c) \geq 2$ for all $a \geq 2 t-c>0$. This is the scenario, as illustrated in 


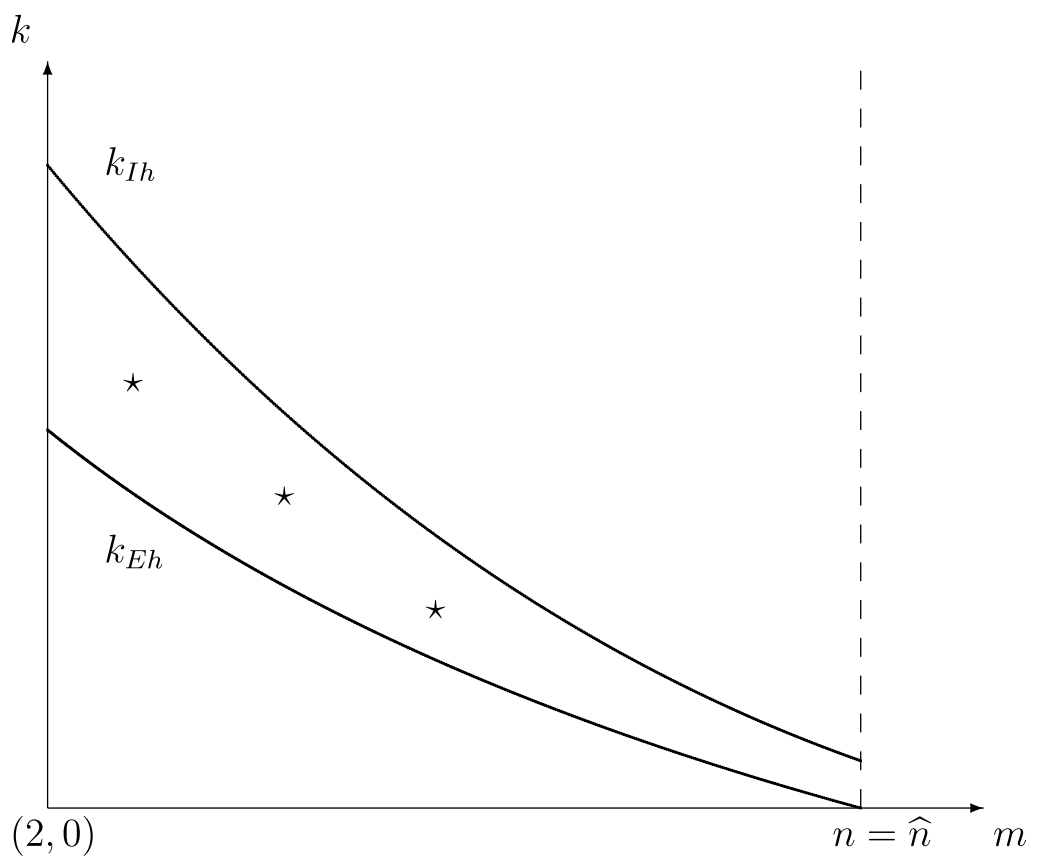

Fig. 6 The stability region for $\gamma=1$

Fig. 6. For instance, if $a=1, c=1 / 5$ and $t=1 / 4, \hat{n}=30$. Accordingly, $k_{\mathrm{Eh}}^{\gamma \rightarrow 1}=0$ when $m=n(=\widehat{n})$. For the same set of numerical values, $k_{\mathrm{Ih}}^{\gamma \rightarrow 1}=0$ at $m=31$, i.e., outside the admissible range.

\subsection{Isoelastic demand}

In this section, we investigate the conditions under which the baseline results hold when the demand is nonlinear. To fix ideas, we focus on the case of isoelastic demand; that is, $p_{\text {iso }}=a /\left[(n-m) p_{b}+m p_{g}\right]$. For the sake of brevity, we will show the existence of the range where a stable coalition exists. Equilibrium quantities are:

$$
q_{g \text {-iso }}^{m}=\frac{a(n-1)[t(n-m)-c(n-m-1)]}{[(n-m) t+c m]^{2}} ; q_{b \text {-iso }}^{n-m}=\frac{a(n-1)[t-m(t-c)]}{[(n-m) t+c m]^{2}},
$$

where subscript iso stands for "isoelastic". The profits of a green firm are:

$$
\pi_{g \text {-iso }}^{m}=\frac{a[t(n-m)-c(n-m-1)]^{2}}{[c m+t(n-m)]^{2}}-k,
$$

while the profits of a brown firm are: 


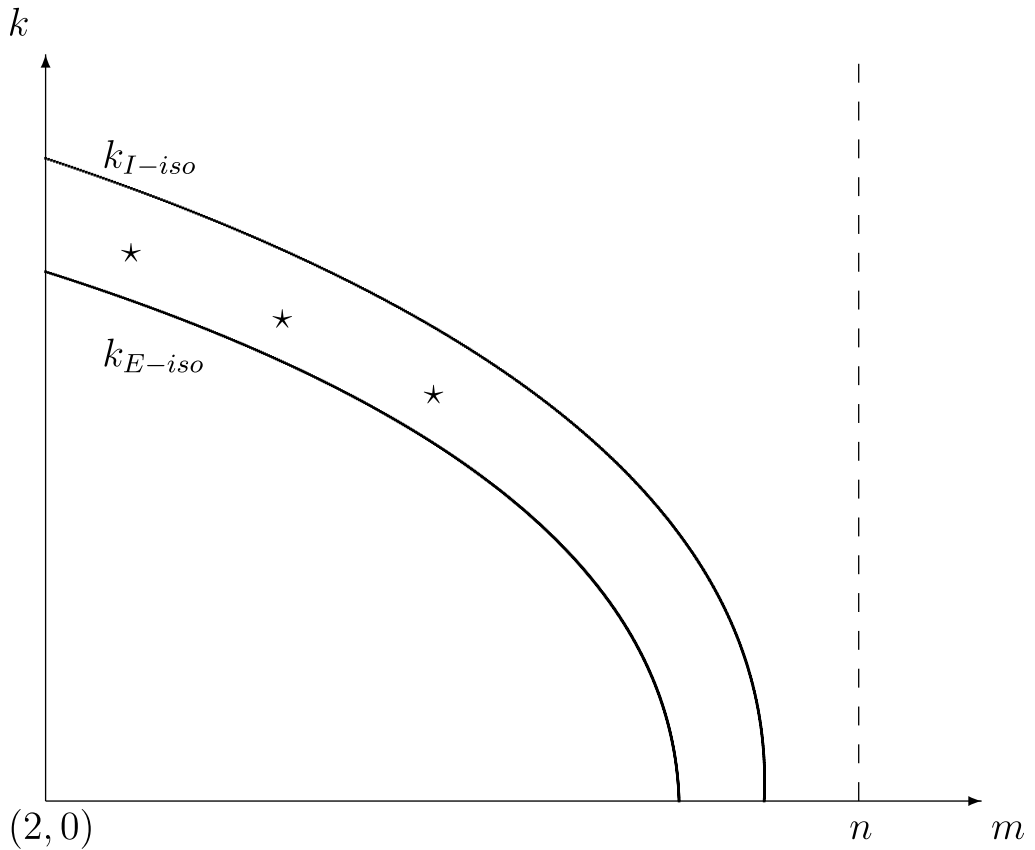

Fig. 7 The stability region with isoelastic demand

$$
\pi_{b \text {-iso }}^{n-m}=\frac{a[t-m(t-m)]^{2}}{[c m+t(n-m)]^{2}} .
$$

Following the usual procedure, the viability condition for the grand green coalition is $k \in\left[0, \underline{k}_{\text {-iso }}\right)$, with $\underline{k}_{\text {-iso }}=a / n^{2}$. Conversely, the grand brown coalition is unstable for all $k \in\left(0, \bar{k}_{\text {-iso }}\right)$, where:

$$
\bar{k}_{\text {-iso }} \equiv \frac{a(n-1)^{2}(t-c)\left[t\left(n^{2}-1\right)-c((n-2) n-1)\right]}{n^{2}[c+(n-1) t]^{2}} .
$$

To determine the stability of the coalition, we derive profits of a deviating green firm and a deviating brown firm, respectively:

$$
\begin{aligned}
\pi_{b \text {-iso }}^{n-m+1} & =\frac{a[(m-2) t-c(m-1)]^{2}}{[c(m-1)+t(n-m+1)]^{2}}, \\
\pi_{g \text {-iso }}^{m+1} & =\frac{a[t(n-m-1)-c(n-m-2)]^{2}}{[c(m+1)+t(n-m-1)]^{2}}-k .
\end{aligned}
$$

Notice that, as in the case with green $\mathrm{R} \& \mathrm{D}$, the condition such that $\pi_{g \mathrm{R}}^{m}=\pi_{b \mathrm{R}}^{n-(m-1)}$ can be found on $k$ instead of $m$. The condition for internal stability, $\pi_{g \mathrm{R}}^{m}-\pi_{b \mathrm{R}}^{n-(m-1)} \geq 0$, holds for $k \leq k_{\mathrm{I}-\mathrm{iso}}$, and the condition for external stability, $\pi_{b \text {-iso }}^{n-m} \geq \pi_{g \text {-iso }}^{m+1}$, holds for $k \geq k_{\mathrm{E} \text {-iso }}$, where a formal definition of $k_{\mathrm{I} \text {-iso }}$ and $k_{\mathrm{E} \text {-iso }}$ is 
given in the appendix. The range of stability is outlined in Fig. 7. Clearly, the incentive to choose the green technology increases with lower investment costs.

We conclude the section by showing the conditions under which the grand green coalition is also socially efficient. We follow the usual procedure: we differentiate social welfare, denoted here as $\mathrm{SW}_{\text {iso }}$, with respect to $m$ and then fix $m=n$, by getting $\left.\frac{\partial \mathrm{SW}_{\text {iso }}}{\partial m}\right|_{m=n} \geq 0$ for $k \leq k_{\text {iso }}^{*}$, where $\left.\frac{\partial \mathrm{SW}_{\text {iso }}}{\partial m}\right|_{m=n}$ and $k_{\text {iso }}^{*}$ are defined in the appendix.

\subsection{Quadratic cost}

In the last extension, we assume that implementing the green technology entails quadratic cost of production. In this case, the profit function of a green firm is $\pi_{g 2}=\left(p-c q_{g 2}\right) q_{g 2}-k, \theta>0$, where subscript 2 refers to "quadratic costs". Market equilibrium is now represented by the following output levels and research effort:

$$
q_{g 2}^{m}=\frac{a+t}{4 c+3 m} ; q_{b 2}^{n-m}=\frac{a(2 c+m)-2 t(c+m)}{(4 c+3 m)(n-m)} .
$$

The individual profits of green and brown firms are, respectively, $\pi_{g 2}^{m}=(a+t)^{2}(c+m) /(4 c+3 m)^{2}-k \quad$ and $\quad \pi_{b 2}^{n-m}=[a(2 c+m)-2 t(c+m)]^{2} /$ $\left[(4 c+3 m)^{2}(n-m)\right]$. In this case, the viability condition for the grand green coalition is $k \in\left[0, \underline{k}_{2}\right), \underline{k}_{2}=(a+t)^{2}(c+n) /(4 c+3 n)^{2}$. Conversely, the grand brown coalition is unstable for all $k \in\left(0, \bar{k}_{2}\right)$, where:

$$
\bar{k}_{2} \equiv \frac{a^{2}\left[4(c+1) n-(4 c+3)^{2}\right]+2 a t\left[4(c+1) n+(4 c+3)^{2}\right]+t^{2}\left[4(c+1) n-(4 c+3)^{2}\right]}{4(4 c+3)^{2} n} .
$$

To determine the stability of the coalition, we derive profits of a deviating green firm and a deviating brown firm, respectively:

$$
\begin{aligned}
\pi_{b 2}^{n-m+1} & =\frac{[a(2 c+m-1)-2 t(c+m-1)]^{2}}{(4 c+3 m-3)^{2}(n-m+1)}, \\
\pi_{g 2}^{m+1} & =\frac{(a+t)^{2}(c+m+1)}{(4 c+3 m+3)^{2}}-k .
\end{aligned}
$$

The condition for internal stability, $\pi_{g 2}^{m}-\pi_{b 2}^{n-(m-1)} \geq 0$, holds for $k \leq k_{\mathrm{I} 2}$, whereas the condition for external stability $\pi_{b 2}^{n-m} \geq \pi_{g 2}^{m+1}$, holds for $k \geq k_{\mathrm{E} 2}$ (see the appendix for the formal derivation). Figure 8 shows the results, which are similar to those in Sect. 5.5.

We finally investigate the conditions under which a grand green coalition is socially efficient. Differentiating social welfare, denoted here as $\mathrm{SW}_{2}$, with respect to $m$ and then fixing $m=n$, we get $\left.\frac{\partial \mathrm{SW}_{2}}{\partial m}\right|_{m=n} \geq 0$ for all $k \leq k_{2}^{*}$, where $\left.\frac{\partial \mathrm{SW}_{2}}{\partial m}\right|_{m=n}$ and $k_{2}^{*}$ are formally defined in the appendix. 


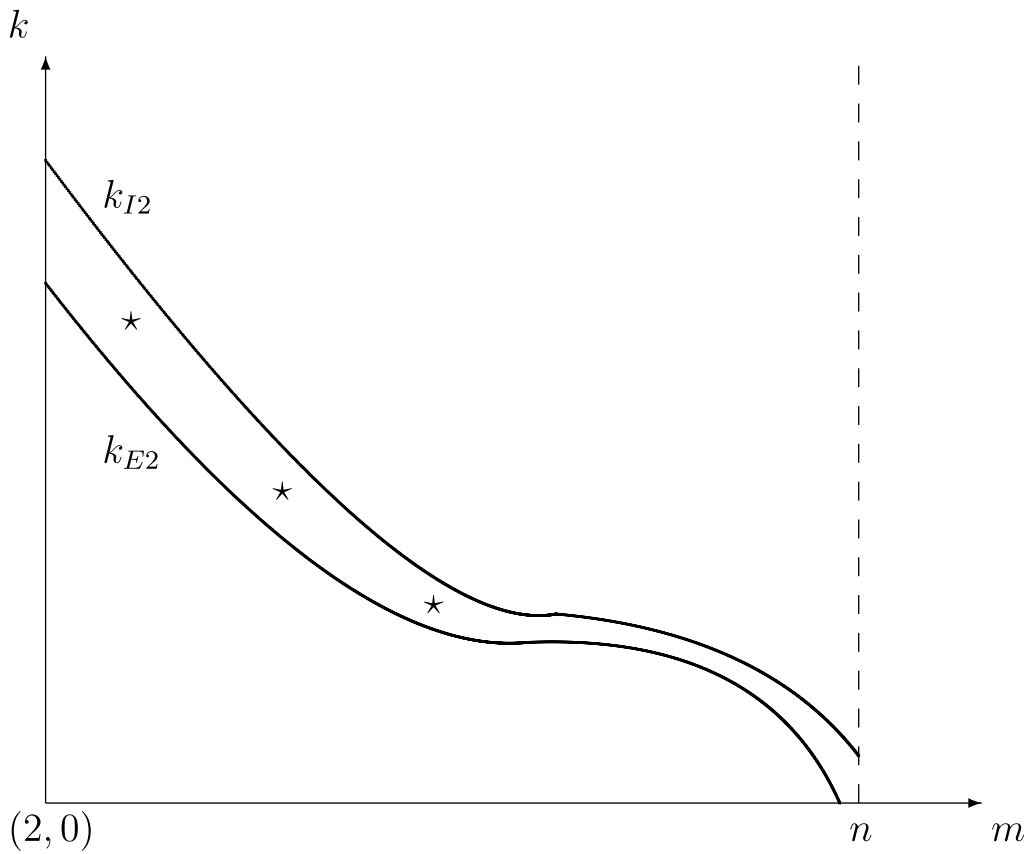

Fig. 8 The stability region with quadratic costs

\section{Concluding remarks}

In this paper, we have examined the emergence of the Porter Hypothesis in a large oligopoly where the adoption of green technologies is endogenously determined as a result of competition among coalitions. In a baseline Cournot model and then in several modifications and extensions, also including price competition, we have identified the conditions on the two key parameters of the model, the emission tax and the exogenous R\&D cost of obtaining the green technology, under which the grand green coalition is stable and generates a win-win solution. The conditions emerge in equilibrium if the amount of the $R \& D$ cost is relatively contained. This result validates the Porter Hypothesis in its strong formulation, i.e., the introduction of an environmental policy may in fact increase firms' profits. Notably, one of the infinitely many tax policies delivering the win-win solution is the ex ante welfaremaximising tax rate.

An important point is that our results did not rely on the standard assumption on consumers' environmental awareness. This shows that competition intensified by regulation is sufficient to push green innovation and in turn profits. We hope that our findings will inspire a new, sustainable design of industrial and regulatory policies.

Funding Open access funding provided by Alma Mater Studiorum - Università di Bologna within the CRUI-CARE Agreement. 
Open Access This article is licensed under a Creative Commons Attribution 4.0 International License, which permits use, sharing, adaptation, distribution and reproduction in any medium or format, as long as you give appropriate credit to the original author(s) and the source, provide a link to the Creative Commons licence, and indicate if changes were made. The images or other third party material in this article are included in the article's Creative Commons licence, unless indicated otherwise in a credit line to the material. If material is not included in the article's Creative Commons licence and your intended use is not permitted by statutory regulation or exceeds the permitted use, you will need to obtain permission directly from the copyright holder. To view a copy of this licence, visit http://creativecommons.org/licen ses/by/4.0/.

\section{Appendix}

\section{Formulas of Section 5.1}

\section{Welfare maximisation with respect to $\mathrm{m}$}

Differentiating $\mathrm{SW}_{\mathrm{s}}$ with respect to $m$, we get:

$$
\begin{aligned}
& \left.\frac{\partial \mathrm{SW}_{\mathrm{s}}}{\partial m}\right|_{m=n}=\frac{a^{2} v(n-m)-a\left[c\left(3 m^{2} v+n v(n-4 m)+n+2\right)+s\left(\lambda+v\left(-\left(3 m^{2}-4 m n+n^{2}\right)\right)+\lambda n-1\right)\right]}{(n+1)^{2}}-(s-c) \times \\
& {\left[c\left(-2 m^{3} v+3 m^{2} n v-m(n(n v+2)+3)+(n+1)^{2}\right)+m s\left(v\left(2 m^{2}-3 m n+n^{2}\right)+1\right)+\lambda(n+1) s(-2 m+n+1)\right]-k=0,}
\end{aligned}
$$

for all

$$
k \leq k_{\mathrm{s}}^{*} \equiv \frac{(s-c)\left[c\left(n^{2}+n-1\right)+\lambda\left(n^{2}-1\right) s-n s\right]-a[c(n+2)+s(\lambda+\lambda n-1)]}{(n+1)^{2}} .
$$

\section{Welfare maximisation with respect to $\mathrm{s}$}

Differentiating $\mathrm{SW}_{\mathrm{s}}$ with respect to $s$ yields:

$$
\begin{aligned}
\frac{\partial \mathrm{SW}_{\mathrm{s}}}{\partial s}= & \frac{m a\left(-\lambda+m^{2} v-2 m n v+n^{2} v-\lambda n+1\right)}{(n+1)^{2}} \\
& +\frac{m c\left[m^{3} v-2 m^{2} n v+m\left(-\lambda+n^{2} v-\lambda n+n+2\right)+(\lambda-1)(n+1)^{2}\right]}{(n+1)^{2}} \\
& -\frac{-m s\left[m^{3} v-2 m^{2} n v+m\left(-2 \lambda+n^{2} v-2 \lambda n+1\right)+2 \lambda(n+1)^{2}\right]}{(n+1)^{2}} \\
= & 0,
\end{aligned}
$$

for

$$
\begin{aligned}
s= & s_{\mathrm{s}}^{*} \equiv \frac{a\left[-\lambda+v(m-n)^{2}-\lambda n+1\right]}{-2 \lambda(n+1)(m-n-1)+m v(m-n)^{2}+m}+ \\
& \frac{c\left[m^{3} v-2 m^{2} n v+m\left(n^{2} v-\lambda(n+1)+n+2\right)+(\lambda-1)(n+1)^{2}\right]}{-2 \lambda(n+1)(m-n-1)+m v(m-n)^{2}+m} .
\end{aligned}
$$




\section{Formulas of Section 5.2}

\section{Choke prices}

Comparing $m_{\mathrm{IB}}$ with $n$, we get:

$$
\begin{aligned}
& m_{\mathrm{IB}}-n=\frac{k(2 n+1)^{2}(n+1)^{3}-2 n\left(n^{2}+n+1\right)(c-t)\left[a(4 n+2)+c((n-3) n-1)-\left(n^{2}+n+1\right) t\right]}{n^{2}\left(n^{2}+n+1\right)(t-c)^{2}}>0 \Leftrightarrow \\
& a>a_{\mathrm{IB}} \equiv-\frac{2 n\left(n^{2}+n+1\right)\left[c^{2}\left(n^{2}-3 n-1\right)-2 c(n-1) n t+\left(n^{2}+n+1\right) t^{2}\right]+k(2 n+1)^{2}(n+1)^{3}}{4 n(2 n+1)\left(n^{2}+n+1\right)(c-t)} .
\end{aligned}
$$

Comparing $m_{\mathrm{EB}}$ with $n$ instead, we get:

$$
\begin{aligned}
& m_{\mathrm{EB}}-n=\frac{k(2 n+1)^{2}(n+1)^{3}-2 n\left(n^{2}+n+1\right)(t-c)\left[a(4 n+2)+c\left(n^{2}-n-1\right)-\left(n^{2}+3 n+1\right) t\right]}{4 n^{2}\left(n^{2}+n+1\right)(t-c)^{2}}>0 \Leftrightarrow \\
& a>a_{\mathrm{EB}} \equiv-\frac{2 n\left(n^{2}+n+1\right)\left[c^{2}\left(n^{2}-n-1\right)-2 c n(n+1) t+\left(n^{2}+3 n+1\right) t^{2}\right]+k(2 n+1)^{2}(n+1)^{3}}{4 n(2 n+1)\left(n^{2}+n+1\right)(c-t)} .
\end{aligned}
$$

\section{Welfare maximisation with respect to $m$}

Differentiating $\mathrm{SW}_{b}$ with respect to $m$, we get:

$$
\begin{aligned}
& \left.\frac{\partial \mathrm{SW}_{b}}{\partial m}\right|_{m=n}=\frac{2 n\left[a(2 n+1)^{2}\left(-2 c\left(n^{2}+n+1\right)+n^{2} t+t\right)\right]}{(n+1)^{4}(2 n+1)^{2}}+ \\
& \frac{2 n\left[c^{2}(n(n(n(6-(n-3) n)+8)+5)+1)+c n^{2}\left(1-3 n^{2}\right) t+n(n+1)^{4} t^{2}\right]}{(n+1)^{4}(2 n+1)^{2}} \\
& -\frac{k(n+1)^{4}(2 n+1)^{2}}{(n+1)^{4}(2 n+1)^{2}} \geq 0,
\end{aligned}
$$

for all

$$
k \leq k_{b}^{*} \equiv \frac{2 n\left[a(2 n+1)^{2}\left(-2 c\left(n^{2}+n+1\right)+n^{2} t+t\right)+c^{2}(n(n(n(6-(n-3) n)+8)+5)+1)+c n^{2}\left(1-3 n^{2}\right) t+n(n+1)^{4} t^{2}\right]}{(n+1)^{4}(2 n+1)^{2}} .
$$

\section{Derivation of $a_{b}^{*}$}

Comparing $\widehat{k}$ with $k^{*}$, we find that $\hat{k}>k^{*}$ for $a>a_{b}^{*}$, where:

$$
a_{b}^{*} \equiv \frac{c^{2} n(n(n(5-2(n-1) n)+7)+4)+c n(n(n(n(2 n-5)-8)-9)-6) t+(n+1)(n(n(7 n+8)+7)+1) t^{2}}{(2 n+1)\left(2 c n\left(n^{2}+n+1\right)+n(3 n+2) t+t\right)} .
$$




\section{Formulas of Section 5.3}

\section{Stability conditions}

The condition for internal stability, $\pi_{g \mathrm{R}}^{n-m}-\pi_{b \mathrm{R}}^{n-m+1} \geq 0$, holds for $k \leq k_{\mathrm{IR}}$, where:

$$
k_{\mathrm{IR}} \equiv \frac{3[a+c(m-n-1)+t(n-m)]^{2}(4 m-n-5)^{2}-[a-3 c(m-1)+(3 m-4) t]^{2}(4 m-n-1)^{2}}{(4 m-n-1)^{2}(4 m-n-5)^{2}} .
$$

The condition for external stability instead, $\pi_{b \mathrm{R}}^{n-m} \geq \pi_{g \mathrm{R}}^{m+1}$, holds for $k \geq k_{\mathrm{ER}}$, where:

$$
k_{\mathrm{ER}} \equiv \frac{3[a+(c-t)(m-n)-t]^{2}(4 m-n-1)^{2}-[a-3 c m+(3 m-1) t]^{2}(4 m-n+3)^{2}}{(4 m-n+3)^{2}(4 m-n-1)^{2}} .
$$

The range in which the coalition is stable exists if $k_{\mathrm{IR}}>k_{\mathrm{ER}} \Leftrightarrow t>\max \left\{0, \hat{t}_{\mathrm{R}}\right\}$, where:

$$
\begin{aligned}
\widehat{t}_{\mathrm{R}} \equiv & \frac{1}{384 m^{4}-32 m^{3}(15 n+11)+24 m^{2}\left(9 n^{2}+26 n-15\right)-6 m\left(7 n^{3}+41 n^{2}-3 n-37\right)+3 n^{4}+28 n^{3}+18 n^{2}-132 n+3} \times \\
& {\left[2 a\left(64 m^{3}-48 m^{2}(n+5)+12 m\left(n^{2}+10 n+9\right)-n^{3}-15 n^{2}-27 n+51\right)+\right.} \\
& \left.3 c\left(128 m^{4}-160 m^{3}(n+1)+8 m^{2}\left(9 n^{2}+30 n+5\right)-2 m\left(7 n^{3}+45 n^{2}+37 n-1\right)+n^{4}+10 n^{3}+16 n^{2}-26 n-33\right)\right] .
\end{aligned}
$$

\section{Welfare maximisation with respect to $m$}

Differentiating $\mathrm{SW}_{\mathrm{R}}$ with respect to $m$ yields:

$$
\begin{aligned}
\left.\frac{\partial \mathrm{SW}_{\mathrm{R}}}{\partial m}\right|_{m=n}= & \frac{a\left[3 c(3 n+2)(5 n+1)-2 a^{2}(15 n+1)+[3(5-12 n) n-1] t\right]}{(3 n-1)^{3}} \\
& +\frac{-3 c^{2}[3 n[n(3 n+2)+2]+1]+3 c n\left(9 n^{2}+3 n-2\right) t-k(3 n-1)^{3}}{(3 n-1)^{3}} \\
\geq & 0,
\end{aligned}
$$

for all $t \geq t_{\mathrm{R}}^{*}$, where:

$$
t_{\mathrm{R}}^{*} \equiv \frac{a^{2}(30 n+2)-3 a c(3 n+2)(5 n+1)+3 c^{2}[3 n[n(3 n+2)+2]+1]+k(3 n-1)^{3}}{(3 n-1)[3 c n(3 n+2)+a-12 a n]} .
$$

\section{Formulas of Section 5.4}

\section{Stability conditions}

The condition for internal stability, $\pi_{g \mathrm{~h}}^{n-m}-\pi_{b \mathrm{~h}}^{n-m+1} \geq 0$, holds for $k \leq k_{\mathrm{Ih}}$, where:

$$
k_{\mathrm{Ih}} \equiv \frac{[(a-c)(m-n-1)-\gamma(a-t)(m-n)]^{2}}{\left[\left(\gamma^{2}-1\right) m(m-n)+n+1\right]^{2}}-\frac{[\gamma(m-1)(a-c)+m(t-a)]^{2}}{\left[\gamma^{2}(m-1)(m-n-1)+m(-m+n+2)\right]^{2}} .
$$


The condition for external stability instead, $\pi_{b \mathrm{~h}}^{n-m} \geq \pi_{g \mathrm{~h}}^{m+1}$, holds for $k \geq k_{\mathrm{Eh}}$, where:

$$
k_{\mathrm{Eh}} \equiv \frac{[(a-c)(n-m)+\gamma(a-t)(m-n+1)]^{2}}{\left[\gamma^{2}(m+1)(m-n+1)+(m+2)(n-m)\right]^{2}}-\frac{[\gamma m(a-c)+(m+1)(t-a)]^{2}}{\left[\left(\gamma^{2}-1\right) m(m-n)+n+1\right]^{2}} .
$$

\section{Formulas of Section 5.5}

\section{Stability conditions}

The condition for internal stability, $\pi_{g \mathrm{R}}^{m}-\pi_{b \mathrm{R}}^{n-(m-1)} \geq 0$, holds for $k \leq k_{I-i s o}$, where:

$$
k_{I-i s o} \equiv \frac{a(c(m-n+1)+t(n-m))^{2}}{(c m+t(n-m))^{2}}-\frac{a(c(-m)+c+(m-2) t)^{2}}{(c(m-1)+t(-m+n+1))^{2}} .
$$

The condition for external stability instead, $\pi_{b-i s o}^{n-m} \geq \pi_{g-i s o}^{m+1}$, holds for $k \geq k_{E-i s o}$, where:

$$
k_{E-i s o} \equiv \frac{a(c(m-n+2)+t(-m+n-1))^{2}}{(c(m+1)+t(-m+n-1))^{2}}-\frac{a(c m-m t+t)^{2}}{(c m+t(n-m))^{2}} .
$$

\section{Welfare maximisation with respect to $m$}

Differentiating $\mathrm{SW}_{\text {iso }}$ with respect to $m$ yields:

$$
\left.\frac{\partial \mathrm{SW}_{\mathrm{iso}}}{\partial m}\right|_{m=n}=\frac{a^{2}(n-1)^{2}(v-1)(c-t)-a c(n-1)\left[c^{2}(n-1) n+c\left(2 n-n^{2}\right) t\right]-c^{3} k n^{3}}{c^{3} n^{3}} \geq 0,
$$

for $k \leq k_{\text {iso }}^{*}$, where:

$$
k_{\text {iso }}^{*} \equiv \frac{a(n-1)\left[a(n-1)(v-1)(c-t)+c^{2} n(c(-n)+c+(n-2) t)\right]}{c^{3} n^{3}} .
$$

\section{Formulas of Section 5.6}

\section{Stability conditions}

The condition for internal stability, $\pi_{g 2}^{m}-\pi_{b 2}^{n-(m-1)} \geq 0$, holds for $k \leq k_{\mathrm{I} 2}$, where:

$$
k_{\mathrm{I} 2} \equiv \frac{(4 c+3 m)^{2}(a(2 c+m-1)-2 t(c+m-1))^{2}+(a+t)^{2}(c+m)(4 c+3 m-3)^{2}(m-n-1)}{(4 c+3 m-3)^{2}(m-n-1)(4 c+3 m)^{2}} .
$$

The condition for external stability, $\pi_{b 2}^{n-m} \geq \pi_{g 2}^{m+1}$, holds for $k \geq k_{\mathrm{E} 2}$, where: 


$$
k_{\mathrm{E} 2} \equiv \frac{(a(2 c+m)-2 t(c+m))^{2}(4 c+3 m+3)^{2}+(a+t)^{2}(c+m+1)(4 c+3 m)^{2}(m-n)}{(4 c+3 m)^{2}(m-n)(4 c+3 m+3)^{2}} .
$$

\section{Welfare maximisation with respect to $m$}

Differentiating $\mathrm{SW}_{2}$ with respect to $m$ yields:

$$
\left.\frac{\partial \mathrm{SW}_{2}}{\partial m}\right|_{m=n}=\frac{-4 c^{2}(v(a-t)(a+t)+36 k n)+c n(-(a+t)(-2 v(t-2 a)-5(a+t))-108 k n)-64 c^{3} k-27 k n^{3}}{(4 c+3 n)^{3}} \geq 0
$$

for all $k \leq k_{2}^{*}$, where:

$$
k_{2}^{*} \equiv \frac{c(a+t)[2 v(t(2 c+n)-2 a(c+n))+5 n(a+t)]}{(4 c+3 n)^{3}} .
$$

\section{References}

Ambec, S., \& Barla, P. (2002). A theoretical foundation of the porter hypothesis. Economics Letters, 75, 355-360.

Ambec, S., \& Barla, P. (2006). Can environmental regulations be good for business: An assessment of the porter hypothesis. Energy Studies Review, 14, 42-62.

Ambec, S., Cohen, M., Elgie, S., \& Lanoie, P. (2013). The porter hypothesis at 20: Can environmental regulation enhance innovation and competitiveness? Review of Environmental Economics and Policy, 7, 2-22.

André, F. J., González, P., \& Porteiro, N. (2009). Strategic quality competition and the porter hypothesis. Journal of Environmental Economics and Management, 57, 182-194.

Barrett, S. (1994). Self-enforcing international environmental agreements. Oxford Economic Papers, 46, 878-894.

Braat, L. C., \& Van Lierop, W. F. J. (1987). Economic-ecological modeling. Amsterdam: North Holland.

Carraro, C., \& Siniscalco, D. (1993). Strategies for the international protection of the environment. Journal of Public Economics, 52, 309-328.

Chang, C. H. (2011). The influence of corporate environmental ethics on competitive advantage: The mediation role of green innovation. Journal of Business Ethics, 104, 361-370.

Chen, Y. S. (2008). The driver of green innovation and green image: Green core competence. Journal of Business Ethics, 81, 531-543.

Constantatos, C., \& Herrmann, M. (2011). Market inertia and the introduction of green products: Can strategic effects justify the porter hypothesis? Environmental and Resource Economics, 50, 267-284.

Costa, I., \& Ferrao, P. (2010). A case study of industrial symbiosis development using a middle-out approach. Journal of Cleaner Production, 18, 984-992.

Costa, I., Massard, G., \& Agarwal, A. (2010). Waste management policies for industrial symbiosis development: Case studies in European countries. Journal of Cleaner Production, 18, 815-822.

d'Aspremont, C., Jacquemin, A., Gabszewicz, J. J., \& Weymark, J. (1983). On the stability of collusive price leadership. Canadian Journal of Economics, 16, 17-25.

Donsimoni, M. P. (1985). Stable heterogeneous cartels. International Journal of Industrial Organization, 3, 451-467.

Donsimoni, M. P., Economides, N. S., \& Polemarchakis, H. N. (1986). Stable cartels. International Economic Review, 27, 317-327. 
European Commission. (2017). Progress report, years 2015-2016. https://ec.europa.eu/energy/en/topics/ renewable-energy/progress-reports. Accessed 15 May 2020

Finus, M. (2008). Game theoretic research on the design of international environmental agreements: Insights, critical remarks, and future challenges. International Review of Environmental and Resource Economics, 2, 29-67.

Ford, J. A., Steen, J., \& Verreynne, M.-L. (2014). How environmental regulations affect innovation in the Australian oil and gas industry: Going beyond the porter hypothesis. Journal of Cleaner Production, 84, 204-213.

Fraunhofer Institute on Germany Report. 2013. https://www.ise.fraunhofer.de

Fujiwara, K. (2009). Environmental policies in a differentiated oligopoly revisited. Resource and Energy Economics, 31, 239-247.

Gore, A. (1993). Earth in the balance: Ecology and the human spirit. New York: Penguin.

Horbach, J., \& Rammer, C. (2018). Energy transition in Germany and regional spill-overs: The diffusion of renewable energy in firms. Energy Policy, 121, 404-414.

Jaffe, A. B., Newell, R. G., \& Stavins, R. N. (2003). Technological change and the environment. Handbook of Environmental Economics, 1, 461-516.

Jaffe, A. B., \& Palmer, K. (1997). Environmental regulation and innovation: A panel data study. Review of Economics and Statistics, 79, 610-619.

Katsoulacos, Y., \& Xepapadeas, A. (1995). Environmental policy under oligopoly with endogenous market structure. Scandinavian Journal of Economics, 97, 411-420.

Kim, Y., \& Choi, S. R. (2005). Antecedents of green purchase behaviour: An examination of collectivism, environmental concern and PCE. Advances in Consumer Research, 32, 592-599.

Kleven, H. J., \& Kreiner, C. T. (2006). The marginal cost of public funds: Hours of work versus labor force participation. Journal of Public Economics, 90, 1955-1973.

Laffont, J. J. (2005). Regulation and development. Cambridge: Cambridge University Press.

Laffont, J. J., \& Tirole, J. (1986). Using cost observation to regulate firms. Journal of Political Economy, 94, 614-641.

Lambertini, L. (2013). Oligopoly, the environment and natural resources. London: Routledge.

Lambertini, L. (2017). Green innovation and market power. Annual Review of Resource Economics, 9, 231-252.

Lambertini, L., \& Tampieri, A. (2012). Vertical differentiation in a Cournot industry: The porter hypothesis and beyond. Resource and Energy Economics, 34, 374-380.

Lanoie, P., Laurent-Lucchetti, J., Johnstone, N., \& Ambec, S. (2011). Environmental policy, innovation and performance: New insights on the porter hypothesis. Journal of Economics and Management Strategy, 20, 803-842.

Levelized cost of electricity renewable energy technologies. Fraunhofer. 2013. http://www.ise.fraunhofer .de/en/publications/veroeffentlichungen-pdf-dateien-en/studien-und-konzeptpapiere/study-levelizedcost-of-electricity-renewable-energies.pdf. Accessed 15 May 2020

Majumdar, S. K., \& Marcus, A. A. (2001). Rules versus discretion: The productivity consequences of flexible regulation. Academy of Management Journal, 44, 170-179.

Matsumura, T., \& Tomaru, Y. (2013). Mixed duopoly, privatization, and subsidization with excess burden of taxation. Canadian Journal of Economics, 46, 526-554.

Meadows, D.H, Meadows, D.L., Randers, J., \& Behrens, W.W. (1972). The Limits to Growth, New York, Universe Books.

Milliman, S. R., \& Prince, R. (1989). Firm incentives to promote technological change in pollution control. Journal of Environmental Economics and Management, 17, 247-265.

Mohr, R. D. (2002). Technical change, external economies, and the porter hypothesis. Journal of Environmental Economics and Management, 43, 158-168.

OpenEI Transparent Cost Database. (2015). http://en.openei.org/apps/TCDB/. Accessed 15 May 2020

Palmer, K., Oates, W., \& Portney, P. (1995). Tightening environmental standards: The benefit-cost or the no-cost paradigm? Journal of Economic Perspectives, 9, 119-132.

Partzsch, L. (2009). Smart regulation for water innovation: The case of decentralized rainwater technology. Journal of Cleaner Production, 17, 985-991.

Popp, D. (2005). Uncertain R\&D and the porter hypothesis. Contribution Economic Analysis and Policy, 4,6 .

Porter, M. E. (1991). America's Green Strategy. Scientific American, 264, 168.

Porter, M. E., \& van der Linde, C. (1995a). Toward a new conception of the environment-competitiveness relationship. Journal of Economic Perspectives, 9, 97-118. 
Porter, M. E., \& van der Linde, C. (1995b). Green and competitive: Ending the stalemate. Harvard Business Review (September-October), 215, 120-134.

Powering the Nation. Parsons Brinckerhoff. (2010). http://www.pbworld.com/regional/uk_europe_speci alty/. Accessed 15 May 2020

Reitman, V. (1992). Green products sales seem to be wilting. The Wall Street Journal, $220,18$.

Requate, T., \& Unold, W. (2003). Environmental policyincentives to adopt advanced abatement technology: Will the true ranking please stand up? European Economic Review, 47, 125-146.

Rexhäuser, S., \& Rammer, C. (2014). Environmental innovations and firm profitability: Unmasking the porter hypothesis. Environmental and Resource Economics, 57, 145-167.

Rubashkina, Y., Galeotti, M., \& Verdolini, E. (2015). Environmental regulation and competitiveness: Empirical evidence on the porter hypothesis from European manufacturing sectors. Energy Policy, $83,288-300$.

Sato, S., Matsumura, T. (2017). Shadow cost of public funds and privatization policies, MPRA working paper, 81054

Simpson, R. D. (1995). Optimal pollution taxation in a Cournot duopoly. Environmental and Resource Economics, 6, 359-369.

Thoron, S. (1998). Formation of a coalition-proof stable cartel. Canadian Journal of Economics, 31, $63-76$.

Wagner, M. (2003). The porter hypothesis revisited: A literature review of theoretical models and empirical tests. Center for Sustainability Management.

Publisher's Note Springer Nature remains neutral with regard to jurisdictional claims in published maps and institutional affiliations. 